\title{
A process synthesis tool for WWTP - An application to design sustainable energy recovery facilities
}

Behera, Chitta Ranjan; Al, Resul; Gernaey, Krist V.; Sin, Gürkan

Published in:

Chemical Engineering Research and Design

Link to article, DOI:

10.1016/j.cherd.2020.02.014

Publication date:

2020

Document Version

Peer reviewed version

Link back to DTU Orbit

Citation (APA):

Behera, C. R., Al, R., Gernaey, K. V., \& Sin, G. (2020). A process synthesis tool for WWTP - An application to design sustainable energy recovery facilities. Chemical Engineering Research and Design, 156, 353-370. https://doi.org/10.1016/j.cherd.2020.02.014

\section{General rights}

Copyright and moral rights for the publications made accessible in the public portal are retained by the authors and/or other copyright owners and it is a condition of accessing publications that users recognise and abide by the legal requirements associated with these rights.

- Users may download and print one copy of any publication from the public portal for the purpose of private study or research.

- You may not further distribute the material or use it for any profit-making activity or commercial gain

- You may freely distribute the URL identifying the publication in the public portal 


\title{
A process synthesis tool for WWTP - An application to design sustainable energy recovery facilities
}

\author{
Chitta Ranjan Behera, Resul Al, Krist V. Gernaey, Gürkan Sin *
}

4

5 Process and Systems Engineering Center (PROSYS), DTU Chemical Engineering, Technical

6 University of Denmark, 2800 Kgs. Lyngby, Denmark

*Corresponding Author: Department of Chemical and Biochemical Engineering, Technical

8 University of Denmark, Building 229, 2800 Kgs. Lyngby, Denmark, Email: gsi@kt.dtu.dk, Tel:

$9+4545252980$

10

\section{NOMENCLATURE}

\begin{tabular}{ll}
\hline Symbol & Description \\
\hline AD & Anaerobic digestion \\
CAPEX & Capital expenditure \\
DW & Dewatering \\
ERBF & Enhanced rotating belt filter \\
GHGs & Greenhouse gases \\
HRAS & High-rate activated sludge \\
HRT & Hydraulic retention time \\
IFAS & Integrated fixed-film activated sludge \\
LHS & Latin hypercube sampling \\
MC & Monte Carlo \\
MI(N)LP & Mixed integer nonlinear programming \\
MLE & Modified Ludzack-Ettinger \\
NER & Net energy recovery \\
NLR & Nitrogen loading rate \\
ODEs & Ordinary differential equations \\
OPEX & Operational expenditure \\
PC & Primary clarifier \\
\hline
\end{tabular}




\begin{tabular}{|c|c|}
\hline PDEs & Partial differential equations \\
\hline RBF & Rotating belt filter \\
\hline SI & Supporting information \\
\hline SOR & Surface overflow rate \\
\hline SRT & Sludge retention time \\
\hline TAC & Total annualized cost \\
\hline $\mathrm{TH}$ & Thickener \\
\hline$Q_{i n}$ & Influent flow rate \\
\hline$n$ & Plant life cycle \\
\hline$m_{\mathrm{CH}_{4}}$ & Mass flow rate of methane $\left(\mathrm{kg} \mathrm{CH}_{4} / \mathrm{d}\right)$ gas \\
\hline$\phi$ & Methane gas to the energy conversion factor \\
\hline$\psi$ & $\mathrm{CO}_{2}$ equivalent conversion factor \\
\hline$n_{R B F}$ & Number of RBF units \\
\hline$l$ & Plant layout \\
\hline$\tilde{l}$ & Set of top five plant layouts \\
\hline$f_{i}$ & Objective function \\
\hline$w_{i}$ & Weights for the objective function \\
\hline$V$ & Volume of reactor \\
\hline$g$ & Process constraint \\
\hline$y$ & Technology type \\
\hline$x$ & State variable \\
\hline$x_{\mathrm{o}}$ & Initial condition of the state variable \\
\hline$u$ & Input \\
\hline$h$ & Process model \\
\hline$d$ & Design parameter \\
\hline$\hat{d}$ & Set of best design parameters of each layout \\
\hline$\mu$ & Utility consumption \\
\hline$\theta$ & Conversion efficiency \\
\hline$\beta$ & Kinetic parameter \\
\hline$\gamma$ & Stoichiometry coefficient \\
\hline
\end{tabular}




\section{ABSTRACT}

14 The objective of this paper is to present a new process synthesis tool to systematically synthesize, design,

15 and evaluate plant layouts for early-stage design/retrofit of wastewater treatment plants. The tool relies upon

16 an integrated methodology with the following key features: (1) first-principles mechanistic models used to

17 simulate existing and emerging technologies. This key innovation ensures predictive capability, 2) Monte

18 Carlo technique and simulation-based optimization techniques for handling the resulting computational

19 complexity effectively, 3) a systematic initialization algorithm developed for plant-wide simulation, 4)

20 optimizing design parameters, operational conditions, and plant layout simultaneously. Moreover,

21 stochastic analysis is performed to verify the robustness of plant configuration and design proposed by the

22 tool. Finally, using the tool, three real case studies are analyzed to demonstrate the design retrofit of WWTP

23 to the energy recovery plant.

\section{KEYWORDS}

25 Process synthesis tool, Simulation-based optimization, Process design, Stochastic analysis, Monte Carlo 26 simulation, Energy recovery

\section{RESEARCH HIGHLIGHTS}

28 - A novel tool to synthesize, design and optimize wastewater treatment plant layouts

29 - Handle multi-scale and multi-type process models

30 - A systematic initialization algorithm for dealing with plant-wide model simulations

31 - A holistic evaluation approach consisting of energy recovery, economic and sustainability

32 - The tool successfully applied to a retrofitting study of 3 full-scale plants 


\section{INTRODUCTION}

36 In the $21^{\text {st }}$ century, as we have started to acknowledge that wastewater is a renewable resource from which

37 water, energy, and materials can be recovered, the demand for building new resources recovery facilities 38 or retrofitting existing wastewater treatment plants (WWTPs) are gaining interest among various

39 stakeholders (such as utility managers, operators, regulators, end-users etc.). The primary problems in

40 deploying sustainable resource recovery technologies are lack of systematic planning and design

41 methodology, economic feasibility, market pull among others (Guest et al., 2009). Since the inception of

42 the activated sludge process, the horizon of innovative wastewater treatment solutions keeps on increasing

43 and so does the priorities. Several times the priorities set by the stakeholders are self-conflicting, which

44 further narrow the flexibility of decision-makers, for example, achieving stringent effluent quality and also

45 reducing the total cost of the project. Therefore competing objectives must be identified and trade-offs

46 made. Often design professionals are confronted with the fact that their proposed designs are not producing

47 desired results which may be due to unforeseeable social, economic, and legal changes (Dominguez and

48 Gujer, 2006). Moreover, some studies (Dominguez and Gujer, 2006; Vanrolleghem et al., 1996) advocate

49 that current design practices to build WWTP are not suitable to handle future developments as the

50 interaction among catchment area, sewer system, WWTP, regulatory body and public is hardly understood

51 and considered during the plant design stage. To handle the growing complexity, the decision-makers do

52 not have sufficient tools to carry out holistic analysis and are many times satisfied with the traditional

53 solutions based on heuristic approach (Balkema et al., 2002; Chamberlain et al., 2014; Guest et al., 2009).

54 Resource recovery from WWTPs in the form of energy (heat and/or electricity) has been a common

55 practice among developed nations, and the focus is now moving towards producing surplus energy from

56 an existing plant. For that matter a country like Denmark is leading to demonstrate the technical know-

57 how to build an energy recovery facility to other countries. Retrofitting existing plants or building new

58 recovery plants require a systematic understanding of COD diversion by adaptation of emerging

59 technologies such as Anammox technology and enhanced primary treatment technologies. Moreover, their

60 design and integration need to be optimized in order to maximize energy recovery and at the same time

61 respecting other constraints.

62 A process synthesis tool, which can also be called as decision support systems (DSS), has been 63 acknowledged as a realistic tool in the wastewater treatment field for various decision making process, 64 such as process synthesis, designing, control and monitoring (Bozkurt et al., 2015; Castillo et al., 2016b; 65 Comas et al., 2004; Hamouda et al., 2009; Poch et al., 2004; Shim et al., 2002). DSS is an information 66 system which integrates database, models, expert knowledge and user interface, and aims to provide an 
67 insightful platform where decision-makers can analyze and compare various designs and layouts of 68 wastewater treatment plant. The typical implementation time spend on building a new WWTP varies from 696 to 8 years and $13-18 \%$ of the time ( 1 year) is spend on facility planning and preliminary design of 70 plant (WEF, 2018). During this phase, evaluating alternative technologies as well as plant layouts is one 71 of the critical milestones. Therefore selecting a robust plant layout which can recover resources from 72 wastewater and at the same time withstand the unforeseeable uncertainty (such as climate change, stringent 73 laws, etc.) is a clear expectation from design engineers and decision-makers.

74 Several studies (as summarized in Table 1) have been carried out to address wastewater process synthesis 75 and design by considering different objectives such as economic, operational, and environmental 76 feasibility. Most of them solved the problem by applying expert knowledge or empirical models. 77 Moreover, some studies (Alasino et al., 2007; Ferrer et al., 2008; Rivas et al., 2008; Vidal et al., 2002) 78 have used rigorous mechanistic modelling to synthesize and design plant layouts but are limited by the 79 number of technologies (considering present scenarios) used in those study. Since the wastewater 80 treatment technology innovation and its availability in the market is rapidly growing, understanding and 81 handling complexity involved in synthesizing plant layouts with diverse technologies (including both 82 conventional and emerging) is a clear gap needed to be addressed. A study by Bozkurt et al. (2015 b) 83 addressed the above mentioned challenges by including a considerable number of technologies for process 84 synthesis but did not have the flexibility to evaluate the design of treatment units at different influent, 85 operating and design parameter values (such as HRT, SRT, DO set point, etc.).

86 Furthermore, to ensure robustness (i.e., capability to handle unforeseen events) of selected plant layouts, 87 uncertainty analysis is a useful technique which has not been rigorously incorporated in the design process 88 by the other studies listed in Table 1. Additionally, none of the studies evaluate the plant-wide performance 89 objectives in detail (using mechanistic models) while screening alternative technologies. In other words, 90 how a selected plant layout or specific design parameters and operational conditions of a plant layout 91 performs in terms of TN, COD removal in each stage (i.e., primary stage, secondary stage, sludge digestion 92 stage, etc.) is not studied (numerically solved), which may provide additional insight to decision-makers 93 (Flores-Alsina et al., 2012). The underlying reason that the earlier studies did not employ high-fidelity 94 mechanistic models is primary because of computational limitations and/or initialization issues/challenges, 95 which create a significant bottleneck to successfully evaluate/simulate different plant-wide layouts.

96 In this study we used a pragmatic approach such as Monte Carlo (MC) based simulation optimization, that 97 offers a suitable strategy to find optimal design parameters and plant layout, unlike other conventional 98 approaches such as MI(N)LP employed in earlier studies. Since it is decided to use multiscale models, so 
99 the traditional optimization solver may break down due to the degree of nonlinearity and stiffness imposed

100 by the mechanistic model. MC methods are a well-established statistical solution approach albeit so far 101 used predominantly for performing global sensitivity and uncertainty analysis (Al et al., 2019b; Benedetti 102 et al., 2008; Flores-Alsina et al., 2012; Sin et al., 2011). In this study, we employed the MC methods to 103 facilitate exploration of design space (consist of design parameters like HRT and SRT; operational 104 parameters like DO setpoint of each process) quickly and effectively compared to classical numerical 105 optimization algorithms, which relies on the calculation of derivatives of the objective function. Compared 106 to genetic algorithms (such as particle swarm optimization), on the other hand, MC methods require a 107 fewer number of function evaluations.

108 This paper presents a new process synthesis tool (called as SPDLab) which rely upon a proposed integrated 109 methodology to manage the complexity of the problem and find novel and optimal plant layouts along 110 with preliminary designs of each unit. This tool aims to combine several new features: (1) first-principles 111 mechanistic models to simulate various energy recovery-oriented technologies. This key innovation 112 ensures predictive capability, 2) MC technique and simulation-based optimization techniques for handling 113 effectively the resulting computational complexity, 3) a systematic initialization algorithm developed for 114 plant-wide simulation, 4) optimizing design parameters, operational conditions, and plant layout 115 simultaneously. To find an optimal solution, several realistic constraints are imposed, and multiple 116 objectives are formulated and solved under both deterministic (i.e., no data uncertainty) and stochastic 117 (i.e., data uncertainty) conditions. The purpose of the SPDLab tool development is to support the plant 118 designers/decision-makers with providing comprehensive comparison reports on different plant layout 119 alternatives. Moreover, the tool aims to be more user-friendly, where the end-users can reprioritize their 120 objectives by continually learning from the outcomes. Finally, the proposed tool is applied on three real 121 full scale wastewater influents to demonstrate its potential for the design retrofit of energy recovery plants. 


\begin{tabular}{|c|c|c|c|c|c|c|c|}
\hline \multirow[t]{2}{*}{ References } & \multicolumn{3}{|c|}{ Objectives } & \multicolumn{2}{|c|}{ Model fidelity } & \multicolumn{2}{|c|}{ Technology types } \\
\hline & $\begin{array}{c}\text { Process } \\
\text { synthesis }\end{array}$ & $\begin{array}{c}\text { Process } \\
\text { design }\end{array}$ & $\begin{array}{c}\text { Performance } \\
\text { evaluation }^{1}\end{array}$ & Empirical & $\begin{array}{c}\text { Rigorous } \\
\text { mechanistic }\end{array}$ & Conventional & Emerging $^{2}$ \\
\hline (Tang et al., 1997) & $\checkmark$ & $x$ & $x$ & $\checkmark$ & $x$ & $\checkmark$ & $x$ \\
\hline (Vidal et al., 2002) & $\checkmark$ & $x$ & $\checkmark$ & $\checkmark$ & $\checkmark$ & $\checkmark$ & $x$ \\
\hline (Poch et al., 2004) & $\checkmark$ & $x$ & $x$ & $\checkmark$ & $x$ & $\checkmark$ & $x$ \\
\hline (Alasino et al., 2007) & $\checkmark$ & $\checkmark$ & $x$ & $x$ & $\checkmark$ & $\checkmark$ & $x$ \\
\hline (Zeng et al., 2007) & $\checkmark$ & $x$ & $x$ & $\checkmark$ & $x$ & $\checkmark$ & $x$ \\
\hline (Rivas et al., 2008) & $x$ & $\checkmark$ & $x$ & $x$ & $\checkmark$ & $\checkmark$ & $x$ \\
\hline (Ferrer et al., 2008) & $\checkmark$ & $\checkmark$ & $\checkmark$ & $x$ & $\checkmark$ & $\checkmark$ & $x$ \\
\hline (Chamberlain et al., 2014) & $\checkmark$ & $x$ & $x$ & $\checkmark$ & $x$ & $\checkmark$ & $x$ \\
\hline (Bozkurt et al., 2015) & $\checkmark$ & $\checkmark$ & $x$ & $\checkmark$ & $x$ & $\checkmark$ & $\checkmark$ \\
\hline (Puchongkawarin et al., 2015) & $\checkmark$ & $x$ & $x$ & $\checkmark$ & $x$ & $\checkmark$ & $x$ \\
\hline (Rawal and Duggal, 2016) & $\checkmark$ & $x$ & $x$ & $\checkmark$ & $x$ & $\checkmark$ & $x$ \\
\hline (Garrido-Baserba et al., 2016) & $\checkmark$ & $x$ & $x$ & $\checkmark$ & $x$ & $\checkmark$ & $\checkmark$ \\
\hline (Castillo et al., 2016b, 2016a) & $\checkmark$ & $\checkmark$ & $x$ & $\checkmark$ & $x$ & $\checkmark$ & $\checkmark$ \\
\hline This Study & $\checkmark$ & $\checkmark$ & $\checkmark$ & $\checkmark$ & $\checkmark$ & $\checkmark$ & $\checkmark$ \\
\hline
\end{tabular}

\footnotetext{
${ }^{1}$ Performance evaluation objective aims to examine unit wise performance (with sufficiently detailed model) of plant layouts (contains multiple treatment technologies)

${ }^{2}$ Emerging technology types are Anammox, rotating belt filter, A-stage etc.
} 


\section{METHODS}

125 An MC based simulation-optimization framework was developed and evaluated successfully for various 126 chemical engineering related case studies, such as working fluid selection, molecular process, and product 127 design (Frutiger et al., 2019, 2016). The framework was further modified and adapted (as shown in Figure 1) 128 in the context of wastewater treatment plant design. The integrated methodology has six steps which are 129 explained in detail in the following sections. A graphical user interface of the process synthesis (SPDLab) tool 130 is developed and presented in Figure S3 (see SI).

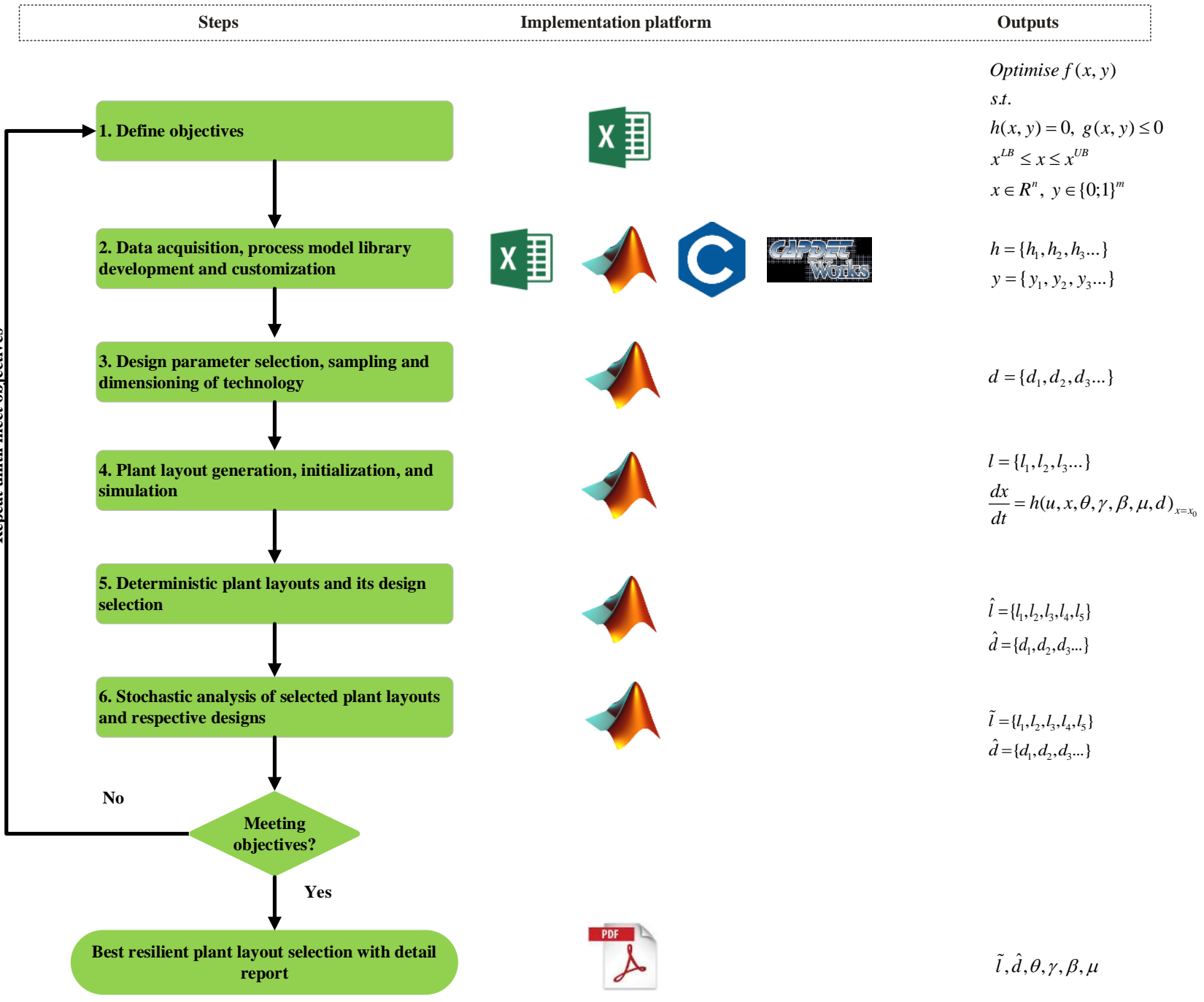

132 Figure 1 Schematic representation of a systematic, integrated methodology used for the development of process synthesis tool shows 133 the steps involved, implementation platform and the outputs from each step. 


\subsection{Step 1: Define objectives}

136 The first and foremost task of a process synthesis tool is to define the objectives. Based on that, the relevant 137 key performance indicators (KPIs) and constraints are framed into a single or multi-objective optimization 138 problem. Users/decision-makers identify whether to retrofit or newly design a plant for a given influent 139 wastewater. Generally, several objectives such as minimizing the total annualized cost (TAC), maximizing net 140 energy recovery (NER), minimizing greenhouse gas emissions (GHGs) are considered as KPIs. Moreover, 141 other aspects, namely complying with stringent effluent discharge limits, operational flexibility, etc. can also 142 be imposed as constraints. Often the relative importance of objectives may not be evident or cannot be 143 generalized due to several factors, such as geopolitical, economic, market, etc. Therefore, finalizing the 144 objectives, which are critical to the solution of the problem, is an iterative process which needs consultation of 145 experts and rigorous investigation of several considerations (as explained above). The outcome of this step can 146 be a decision aiming at retrofitting a specific unit of the existing plant, or extending the capacity of the existing 147 plant, or designing a completely new plant.

\subsection{Step 2: Data acquisition, process model library development, and customization}

149 In the second step, various types of data, such as influent wastewater load (flow, COD, TN etc.), design and 150 operational parameters (HRT, SRT, SOR etc.), utilities and equipment cost (electricity price, chemical cost 151 etc.), space availability (of different WWTP plant site) are collected from design handbooks (Metcalf and 152 Eddy, 2003; WEF, 2018), previous studies (Bozkurt et al., 2016; Lackner et al., 2014; Malovanyy et al., 2015b;

153 Vázquez-Padín et al., 2014), commercial databases (CapdetWorks 4.0), and personal communication with 154 plant managers. These data are further passed through a sanity check to ensure data consistency (using process 155 understanding), and then stored in Excel for executing the subsequent steps. Based on the selected objectives 156 (i.e. in Step1), promising technologies (combination of conventional and emerging) are selected by using the 157 process knowledge gathered from the literature (Batstone et al., 2002; Behera et al., 2018; Gernaey et al., 2014; 158 Lotti et al., 2014; Malovanyy et al., 2015a; Metcalf and Eddy, 2003; Smitshuijzen et al., 2016; Vázquez-Padín 159 et al., 2014; WEF, 2018). For example, the primary treatment units, such as primary clarifier (PC), rotating 160 belt filter (RBF), enhanced rotating belt filter (ERBF) and high rate activated sludge (HRAS), can be 161 considered as potential primary treatment alternative technologies for meeting higher energy production 162 objectives. Likewise for the mainstream, energy-efficient technologies, such as Anammox with different 163 carrier size (granular type named ELANM; AnoxKaldnes $\mathrm{K}_{1}$ carrier-based named IFAS) and conventional 164 activated sludge (MLE type), can be considered. Moreover, anaerobic digestion (AD) and sidestream 165 Anammox (granular type named ELANS) can be considered to boost net energy production in the plant to be 166 designed. Each technology in the customized library can be modeled using a hybrid approach (i.e., empirical 167 as well as mechanistic models) depending on the purpose or level of detail required, for example, if it is 
168 intended to compare the performance unit by unit of alternative plant layouts, then higher fidelity models (such 169 as ADM1, ASMG1, 1-D biofilm, etc.) should be considered to model each technology. Moreover the model 170 libray is flexible and can be customised such that users can add or remove a technology from the model library. 171 It is essential to highlight here that the complexity of the selected model needs to be considered to explain the 172 phenomena in a process unit in a sufficiently detailed manner. The configuration and modelling approach for 173 a customized technology library is presented in Table 2. 


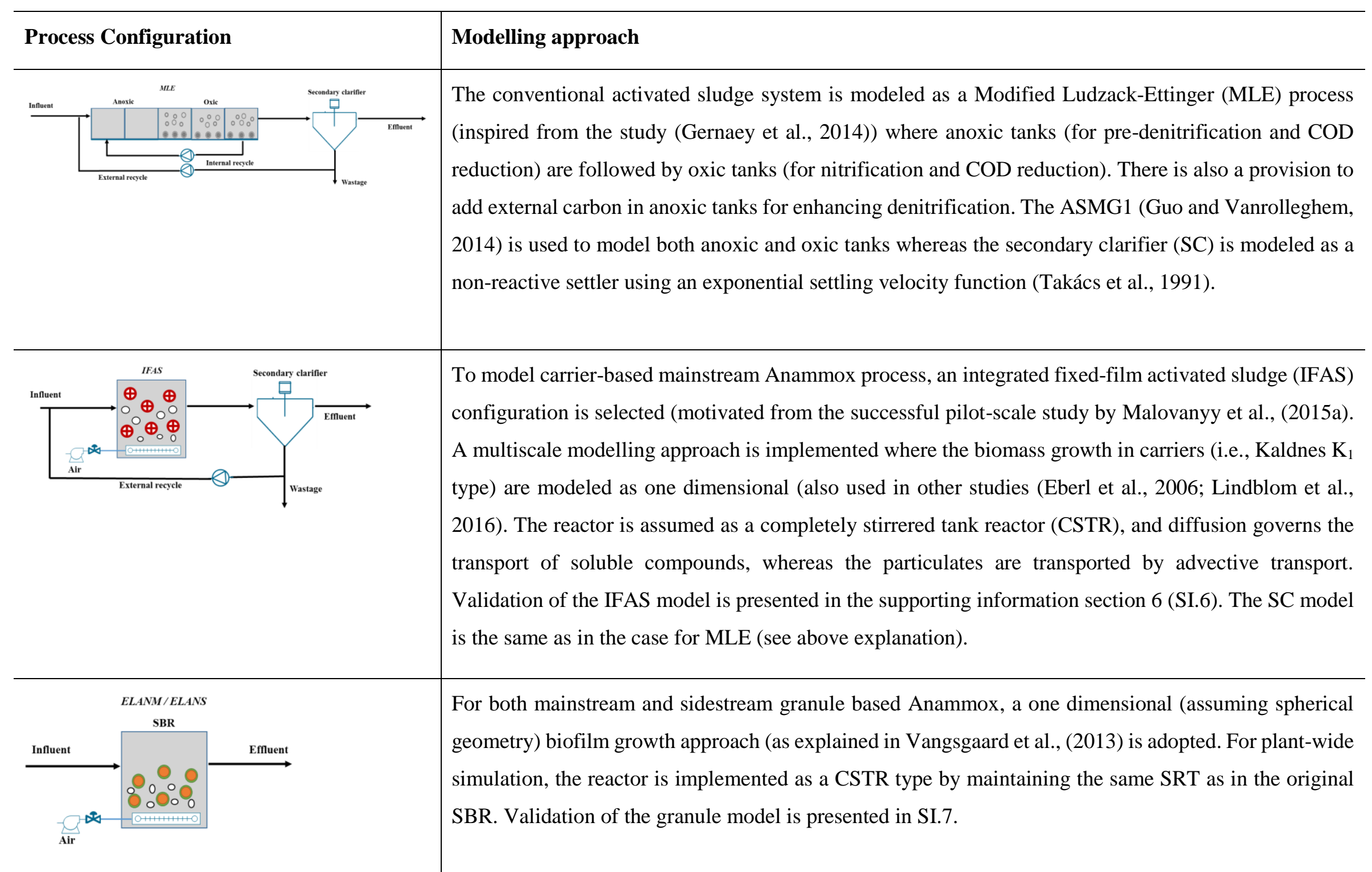




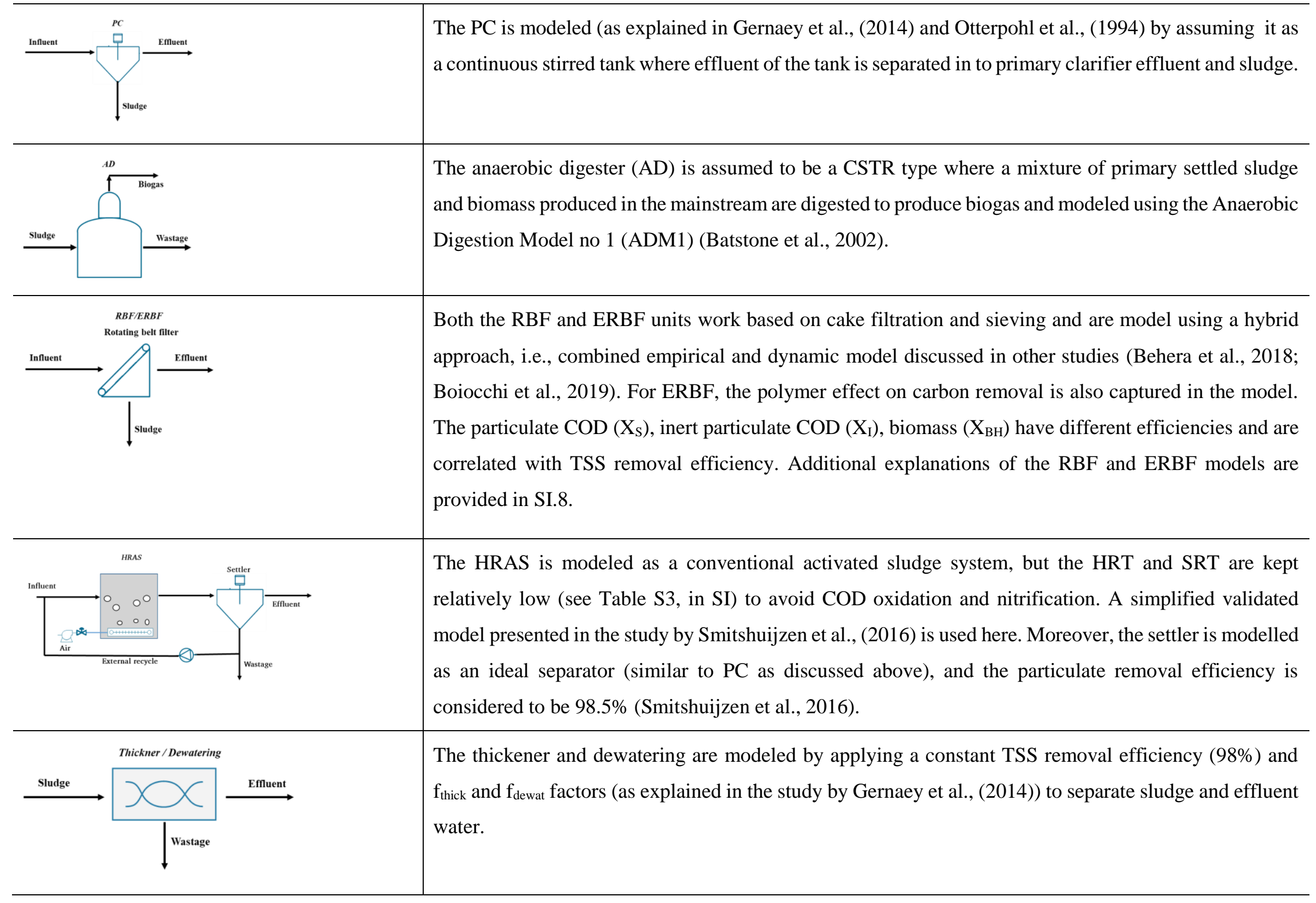




\subsection{Step 3: Design parameter selection, sampling and dimensioning of technology}

\section{Design space exploration using Monte-Carlo procedure}

179 At this stage, the total number of technologies that need to be evaluated is finalized. So to design each 180 technology, relevant design parameters and their suitable range, which is also called the design space, need to 181 be selected. Widely used design parameters are HRT, SRT, SOR, NLR, recycle ratio, volume ratio, etc. whose 182 value can be taken from the database developed in the previous step. It is important to note that the critical 183 design parameters of emerging technology (effectively the scale-up criteria) need to be cross-checked and 184 ideally validated by technology developers. Along with design parameters, some essential/critical operation 185 parameters can be considered while designing an individual unit. For example, when the objective is to harness 186 surplus energy from WWTP, it is not appropriate to maintain a very high DO set point for the aerobic processes, 187 which can add unnecessary energy consumption. Besides, for some processes like Anammox, a high DO 188 setpoint does not help to maintain the stability of the process (Agrawal et al., 2018; Cao et al., 2017; Laureni 189 et al., 2016; Vázquez-Padín et al., 2014; Zhou et al., 2011).

190 MC methods are a well-established statistical sampling technique. The basic principle is to characterize the 191 input parameters; here it is design parameters by a probability distribution function such as normal, uniform 192 or Gaussian-based on the degree of belief concerning where the appropriate values of the parameter will lie 193 (Al et al., 2019b; Sin et al., 2009). For a plant layout, different parameter sets of each unit (such as primary, 194 secondary, etc.) can be combined and sampled using the Latin hypercube sampling (LHS) technique. In this 195 way, the impact of more than one change of a parameter (i.e., the simultaneous variation of design parameters) 196 at a time is captured. Furthermore, it gives a free hand to evaluate all the design parameters to be considered 197 and select the best one for a given objective.

\section{Dimensioning of technology}

199 Each technology's basic design, such as area, volume, height, etc. needs to be calculated for a given wastewater design challenge (i.e., capacity and wastewater composition). The outcome of this is two-fold: Firstly, it will give an idea about the space requirement, and second this information is needed for the subsequent plant-wide simulation to calculate the performance. Therefore each technology can be designed using the following design procedure.

\section{Dimensioning of primary treatment alternatives}


$208 V_{P C}=A_{P C} \times h e i g h t$

209 Likewise, for the RBF and ERBF, a typical Salsness filter (SF2000) model design is adopted. So the number of RBF units and the total volume required for a given wastewater flow rate is calculated by Equations 3 and 4.

$$
n_{R B F}=\frac{Q_{\text {in }}}{Q_{\text {avg }, S F 2000}}
$$

214 The HRAS unit contains an aeration tank for carrying out biosorption, and a clarifier to separate the suspended 215 solids. So, the volume of the HRAS unit (including both aeration tank and settler) can be calculated using 216 Equation 5.

$217 V_{H R A S}=H R T_{H R A S} \times Q_{i n}+0.023 \times Q_{\text {in }}$

Dimensioning of secondary treatment alternatives

Relevant secondary treatment technologies are MLE, ELANM, and IFAS. To design MLE, a conventional approach is used. The MLE has three sections: pre-denitrification (anoxic tank), nitrification and COD oxidation (aerobic tank) and a settler.

223 The volume of the aerobic tank can be calculated by Equation 6 and of the anoxic tank by Equation 7. The 224 total volume of the MLE can be calculated by Equation 8 .

$V_{\text {aerobic }}=H R T_{\text {aerobic }} \times Q_{i n, M L E}$

$V_{\text {anoxic }}=V_{\text {aerobic }} \times V R_{M L E}$

228 The volume of ELANM which operates in SBR mode can be calculated based on nitrogen loading rate (NLR), 229 which is given by Equation 9. For mainstream, the flow rate is quite high, so multiple ELANM tanks should 230 be considered and place either in parallel or stackwise based on the space availability and civil engineering 231 advancement, which depends on local conditions.

$V_{T, E L A N M}=\frac{T N \text { load }}{N L R}$

233 For the IFAS, it has two sections, i.e., an aeration section and a clarifier section and it operates in continuous 234 mode. The volume of the aeration tank can be calculated by Equation 10 and of the clarifier by Equations 1 
and 2. The total volume of the IFAS can be calculated by summing up aerobic tank volume and clarifier 236 volume.

$V_{\text {aerobic,IFAS }}=\frac{T N \text { load }}{N L R}$

\section{Dimensioning of sludge stabilization alternatives}

240 For treating the sludge, AD is used which is assumed to operate in CSTR mode (and also in mesophilic 241 condition) without any recycle. So the HRT and SRT are the same for the AD. The volume of the AD can be 242 calculated based on Equation 11.

$243 \quad V_{A D}=S R T_{A D} \times Q_{i n, A D}$

\section{Dimensioning of sidestream treatment alternatives}

245 The sidestream wastewater, which is also known as reject water from sludge treatment, is rich in TN load and 246 the flow rate quite low compared to the mainstream. Here ELANS can be considered, and its volume can be 247 calculated by using ELANM approach (i.e., Equation 9).

\subsection{Step 4: Plant layout generation, initialization, and simulation}

\section{Superstructure formation}

251 In this step, using all the selected technologies (in step 2) a superstructure is formed (as shown in Figure 4), which consists of different wastewater sources, treatment layers (such as primary, secondary, sludge treatment, 253 etc.) and sinks. The superstructure can be formulated in three different ways, such as alternative collection, 254 combinatorial synthesis, and insight-based synthesis. The alternative collection method uses all the known 255 WWTP layouts based on previous experiences, literature, etc. to form the superstructure. This method heavily 256 depends on experience and does not allow us to evaluate emerging technologies. However, the combinatorial approach generates a superstructure which combines all possible integration of technologies, resulting in vast search space. Many times the superstructure contains redundant and unrealistic plant layouts (for example treating wastewater by bypassing treatment technologies to sink) and increases the required computational effort unnecessarily. The last approach, which is called insight-based, eliminates unfeasible and non-

261 convenient alternatives based on process knowledge and addresses the shortcomings of the above two methods.

262 The insight-based approach has been used for wastewater process synthesis (Al et al., 2019a; Bozkurt et al., 263 2015; Castillo et al., 2016a; Quaglia, 2013) and is also adopted for this study. 
265 Since the methodology uses computational demanding consensus models (such as ADM1, 1D Biofilm, etc.), 266 which can be based on ODEs, PDEs or a combination of both, a common problem encountered during 267 simulation is improper initialization. That is assigning a suitable starting point for the simulation. Moreover, 268 the situation gets worse in a plant-wide simulation where multiple units are connected and recycles are present. 269 Before simulating the plant layout, proper initialization of each unit is required to avoid convergence issues 270 due to the presence of non-linearities and stiffness in the model equations. The initialization is a long-standing 271 issue which is typically solved by a trial and error approach (Gernaey et al., 2014; Pons et al., 1999). Therefore, 272 a systematic initialization strategy is necessarily anticipating the model complexity and the interactions 273 between unit process models during simulations. Furthermore, the proposed design methodology is heavily 274 dependent on plant-wide simulation for optimizing plant layout and design. To handle the initialization issues, 275 a sequential approach is used here. That means once a plant layout is generated from the superstructure, it 276 passes through several steps (as shown in Figure 2) sequentially based on the complexity of the network (i.e., 277 presence of recycle, without recycle, etc.) to find suitable initial conditions for the entire plant. An example 278 based on the steps presented in Figure 2 is illustrated in SI section 5.

279 At this stage, plant layouts, models of each unit, and initial conditions are finalized. So now, steady-state 280 simulations can be performed using the selected influent wastewater. A solver like ode15s (recommended for 281 stiff problems) can be used in the MATLAB Simulink environment to simulate the plant-wide model. All the 282 plant layouts can be simulated several times (i.e., for each LHS sample as discussed in earlier steps), and data 283 on KPIs (such as NER, GHGs, TAC, etc.) can be calculated and stored for the next step analysis. Parallel 284 computing features of MATLAB should be exploited to manage the computational demand and reduce 285 simulation time, i.e. several plant layouts can be simulated simultaneously. 

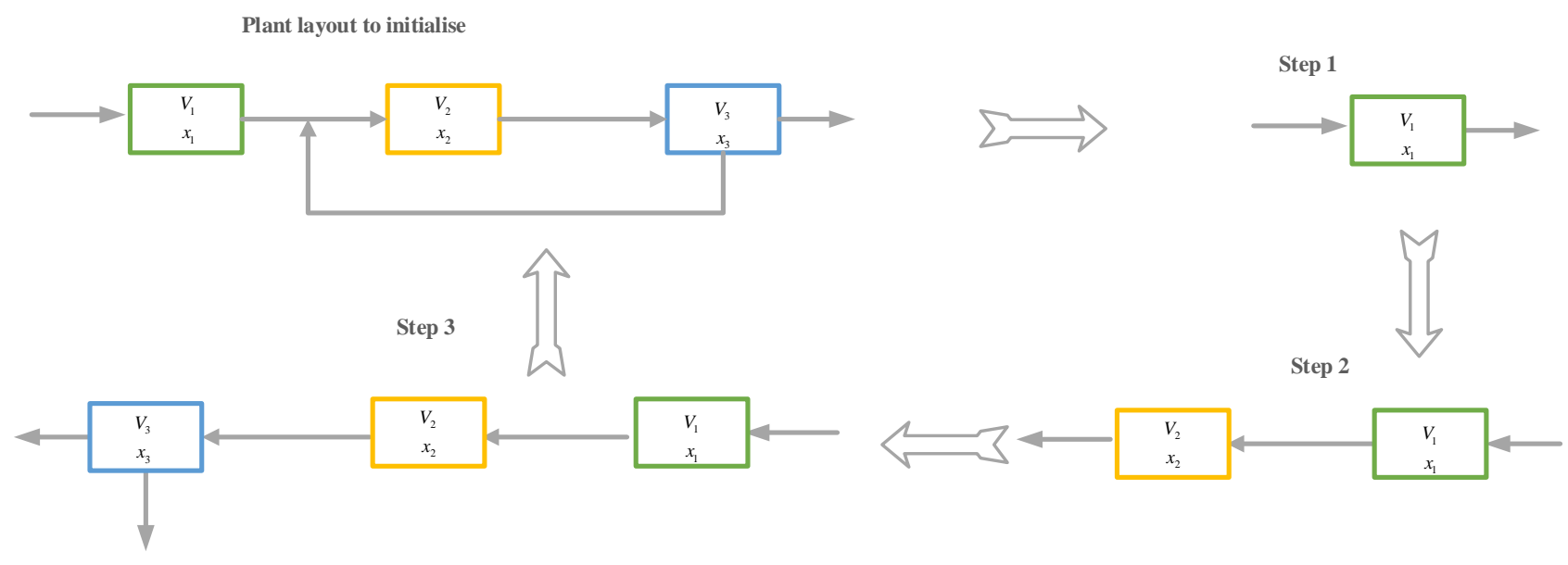

Figure 2 Illustration of sequential approach to initialize a plant layout. Firstly, the plant layout is divided into multiple sub-layouts, and each sub-layout is initialized and simulated to find appropriate initial conditions for the plant layout. Here Vis the volume of the reactor and $x$ is the state variable which needs an initial point.

\subsection{Step 5: Deterministic plant layout and its design selection}

To find the best plant layout and its optimal design parameters under deterministic conditions (i.e., not accounting uncertainty), a two-tier approach can be considered. Firstly, the optimal design parameter set for each plant layout needs to be determined. Then, among the plant layouts, the top five plant layout, candidates should be selected for stochastic analysis. Consequently, it can be treated as bi-level optimization. Therefore, a typical multi-optimization problem can be represented by Equations 12 to 15 .

$\operatorname{maximise} f_{1}:=N E R(\mathrm{kWh} / \mathrm{d})$

minimise $f_{2}:=G H G s\left(\mathrm{~kg} \mathrm{CO}_{2} / \mathrm{d}\right)$

minimise $f_{3}:=$ TAC $\left(\right.$ Euro $\left./ \mathrm{m}^{3} . \mathrm{yr}\right)$

299 Subject to;

$300 \quad$ Process model

$301 \quad h(u, x, \theta, \gamma, \beta, \mu, d)=0$

302 Process constraint

$303 \quad g(x, y) \leq 0$

304 Structure constraints

$x^{L B} \leq x \leq x^{U B}$

$x \in R^{n}, y \in\{0 ; 1\}^{m}$

307 where $f$ is the objective function, $x$ is the continuous variable representing design and operational variables 308 (e.g., HRT, SRT, etc.) defined by their upper $\left(x^{U B}\right)$ and lower bound $\left(x^{L B}\right)$ in a continuous feasible region $R$ 
, $y$ is a binary variable representing alternative technology (e.g., PC, RBF, etc.), $g$ and $h$ are process models

310 (e.g., ADM1) and process constraints (e.g., effluent COD, TN, etc.). $u, \theta, \gamma, \beta, \mu, d$ are the input, conversion

311 efficiency, stoichiometry coefficients, kinetic parameters, utility consumption, and design parameters, 312 respectively.

\section{Selecting an optimal design parameter set}

314 To choose the best design parameter set for each plant layout, the optimization problem, as proposed above, 315 can be solved by a weighted scoring method, as presented in Equation 16. Before that, each objective function 316 value is normalized to eliminate the influence of its magnitude on the solution. The value of each weight ( $\left.317 w_{1}, w_{2}, w_{3} \ldots w_{n}\right)$ can be decided based on the priorities set by the end-user. For example, if all the three 318 objectives are equally important, then $w_{1}=w_{2}=w_{3}=0.33$ should be used. This approach is also used in other 319 applications (Flores-Alsina et al., 2008) and flexible enough to provide solutions when the end-users priority 320 changes or he/she is not sure and want to decide by learning from observations. So finally, the optimal/best 321 design parameter set can be selected by sorting the score (i.e., $J$ ) and picking the maximum or minimum based on the objective. For example, the energy recovery objective should be maximized, whereas total cost and greenhouse gas emission should be minimized. So when a mixture of self-conflicting objectives are present, then a positive sign should be used for maximization objective functions and negative sign should be used for minimization objective functions to calculate a net score $(J)$.

$J=w_{1} \cdot f_{1}+w_{2} \cdot f_{2}+\ldots+w_{n} \cdot f_{n}=\sum_{i=1}^{n} w_{i} \cdot f_{i}$

\section{Ranking top five layouts}

328 Once the design parameters of each plant layout are finalized based on the above procedure, the next task is to 329 rank all the feasible plant layouts and pick the top five layouts for stochastic analysis. The number five is an 330 arbitrary choice, but this number can be reduced or increased based on the computational facility that is 331 available. The ranking of the plant layouts can be done by using a weighted scoring approach similar to the method used for selecting optimal design parameters.

\subsection{Step 6: Stochastic analysis of selected plant layouts and respective designs}

334 Stochastic analysis is performed to verify the robustness of the deterministic solutions (i.e., the outcome of 335 step 5). This is an essential step from a wastewater treatment process synthesis and design point of view 336 because a higher uncertainty in the influent pollutant load (not accounted for during design) arriving at the 
plant can offset the plant performance. The conventional approach used by the design engineer to tackle the

338 uncertainty is by using a safety factor. So, in that approach all the uncertainty sources are lumped to the safety 339 factor, which often leads to an overly conservative design (Belia et al., 2009). To avoid this, an evaluation of 340 all the deterministic solutions needs to be performed under uncertainty. It can be done systematically by 341 following the steps explained below.

\section{Define input uncertainty and perform a plant-wide evaluation}

343 To define input uncertainty, expert knowledge is used. From a wastewater point of view, the influent 344 wastewater data are highly uncertain because of variation in sources of generation (such as domestic and 345 industrial) and due to climate change over the years. More specifically, the flow rate, the temperature, the COD 346 fractions, and the nitrogen fractions in wastewater change over time (daily, weekly, seasonal) and these 347 variations need to be considered while designing a plant. Likewise, temperature variation (affecting the activity 348 of bacteria), cost data (utility cost, tax, etc.), equipment performance over time, etc. can be other sources of 349 uncertainty to consider during the design/retrofit stage. Some studies (Al et al., 2019b; Sin et al., 2009) 350 highlight that influent load is more influential to the performance of the wastewater treatment plant. However, 351 the selection of uncertainty is very subjective and depends on the end users priority and expert knowledge.

352 Once the uncertain parameters are identified, a probability density function (such as normal, uniform, 353 Gaussian, etc.) is assigned based on experimental data/prior knowledge or assumptions for the distribution of 354 individual parameters. Each distribution is described by its mean, minimum, and maximum values, which are 355 later used for MC simulations. The LHS technique by Iman and Conover (1982) is used to generate a fixed 356 number of samples, which also takes into account the correlation among input parameters.

357 The selected plant layouts from the deterministic step (i.e., 5) are simulated several times using the uncertain 358 input samples generated in the previous step by LHS. The outcome is a distribution for each output, for 359 example, the net energy production, total annualized cost, greenhouse gas emission, etc. This analysis further 360 helps to understand the influence of input uncertainty on the KPIs/objectives of the treatment plant to be 361 designed.

\section{Decision making under uncertainty}

363 Using the simulated data generated in plant-wide simulation and simple statistics, such as mean and percentile 364 calculation, the 95\% confidence interval can be calculated for selected KPIs. Along with that, for each plant 365 layout the effluent violation in \% should be calculated to highlight the robustness of the deterministic solutions 366 under uncertain scenarios. The plant layout that violates the effluent discharge limit several times (for example 367 more than 20\%) can be eliminated. Then a ranking approach can be used to find the best and most resilient 
368 plant layout by sorting the objective scores for the remaining layouts (after imposing effluent violation

369 constraints). For a multi-objective problem, the objective score can be calculated by a weighted sum approach

370 as already explained in step 5 (used for the deterministic approach). It is crucial to highlight that for each

371 objective function, mean values (calculated from simulation data) are considered, unlike the single value 372 approach in the deterministic step 5. Based on the priority, the objective scores are either to be minimized or 373 maximized.

\section{CASE STUDIES}

\subsection{The plant configuration}

377 To demonstrate the application of the process synthesis tool, two Danish WWTPs (Avedøre and Lynetten) and 378 one Spanish WWTP (Valladolid) were analyzed. The Avedøre WWTP, located in the west of Copenhagen, 379 can treat 750,000 PE wastewater. The Lynetten WWTP is located in the east of Copenhagen with the capacity 380 to serve 265,000 PE. On the other hand, the Valladolid WWTP, situated in the northwest of Spain, has the 381 largest capacity compared to the Danish WWTPs, with approximately 1,067,000 PE. All the three treatment 382 plants have similar treatment units, such as primary treatment, biological treatment, sludge digestion, etc. (plant 383 layout is shown in Figure 3). The treated wastewater effluents of all three WWTPs are discharged to a 384 receiving water body whereas the produced sludge of the Danish WWTPs is further incinerated in a fluidized 385 bed incineration plant and for the Spanish WWTP it is used for agricultural applications. The current practice 386 is the recovery of energy from the biogas generated in the AD unit as heat and electricity. Both the Avedøre 387 and the Valladolid WWTP use a combined heat and power (CHP) engine to convert biogas to heat and 388 electricity, whereas Lynetten only produces heat using a boiler. The influent wastewater, which enters the three 389 plants, mainly contains organic pollutants, nutrients, suspended solids, etc. For this study, the removal of 390 pollutants, such as COD and TN, is given more importance as their concentrations are higher compared to the 391 other pollutants, and they are omnipresent irrespective of geographical boundaries. Secondly, the process 392 synthesis and design problem is addressed in a step by step manner. For each plant, the yearly influent loads 393 are presented in Table S12 (see SI). 


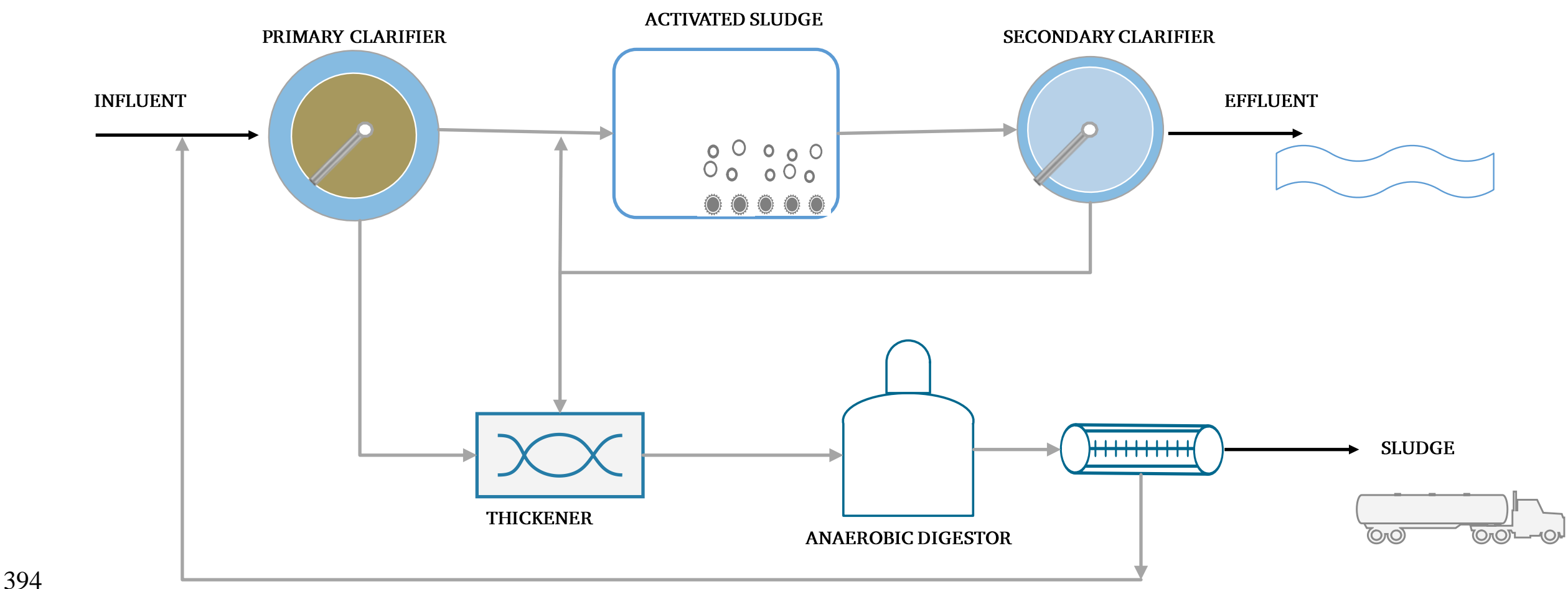




\subsection{Retrofitting scenarios: Objective function formulation}

397 The primary objective is to assess the feasibility of designing energy recovery plants by modifying existing

398 WWTPs, which will be analyzed in two different ways:

1. Maximize net energy recovery challenge: Synthesizing new plant designs based on proper selection and combination of primary, secondary, sludge digestion and reject water treatment units by prioritizing the net energy recovery objective only.

2. Sustainable, economic, and energy-efficient design challenge: Screening diverse treatment units and their combinations by considering sustainability and economic factors in addition to objective 1 (i.e., energy recovery) simultaneously. The cost primarily covers capital and operating expenses (such as electricity, chemical additions, etc.) and sustainability considers emission of GHGs from WWTPs.

407 The end use of effluent water is to discharge it to the water body. So a stringent effluent quality (i.e., COD

$408<100 \mathrm{~g} \mathrm{COD} / \mathrm{m}^{3}, \mathrm{TN}<10 \mathrm{~g} \mathrm{~N} / \mathrm{m}^{3}$ and $\mathrm{NH}_{4}{ }^{+}<1 \mathrm{~g} \mathrm{~N} / \mathrm{m}^{3}$ ) constraints are imposed while finding the optimal 409 solution. The problem is framed as an optimization problem, as shown in Table S13 (see SI).

\section{B.3. Data acquisition, technology selection, and superstructure formulation}

411 Since the methodology uses computational demanding consensus models such as the ASMG1, for process

412 synthesis and design of biological units, it is apparent that the COD and TN concentrations present in the 413 influent wastewater need to be characterized in more detail. For the COD fractionation, the crucial 414 components are inert soluble compounds $\left(\mathrm{S}_{\mathrm{I}}\right)$, inert particulates $\left(\mathrm{X}_{\mathrm{I}}\right)$, readily biodegradable soluble 415 compounds $\left(\mathrm{S}_{\mathrm{S}}\right)$ and biodegradable particulates $\left(\mathrm{X}_{\mathrm{S}}\right)$. For practical purposes, the influent biomass $\left(\mathrm{X}_{\mathrm{BH}}\right.$, $\left.416 \mathrm{X}_{\mathrm{AOB}}, \mathrm{X}_{\mathrm{NOB}}, \mathrm{X}_{\mathrm{AnAoB}}, \mathrm{X}_{\mathrm{P}}\right)$ is assumed to be zero. Similarly, the soluble nitrogen component $\left(\mathrm{S}_{\mathrm{NO} 3}, \mathrm{~S}_{\mathrm{NO} 2}, \mathrm{~S}_{\mathrm{NO}}\right.$, $417 \mathrm{~S}_{\mathrm{N} 2 \mathrm{O}}, \mathrm{S}_{\mathrm{N} 2}$ ) and dissolved oxygen $\left(\mathrm{S}_{\mathrm{O}}\right)$ in influent wastewater is also considered to be zero for all three plants. 418 For the Avedøre and Lynetten WWTPs, the COD and TN are fractionated (as shown in Table 3) by 419 applying a procedure explained elsewhere (Bozkurt et al., 2016). 
Table 3 Influent wastewater loads for the Aved $\phi r e$, Lynetten, and Valladolid wastewater treatment plants. Components having zero concentration are excluded from the table.

\begin{tabular}{lllll}
\hline Parameters & $\begin{array}{l}\text { Avedøre }^{3} \text { (Bozkurt et al., } \\
2016)\end{array}$ & $\begin{array}{l}\text { Lynetten }^{3} \text { (Bozkurt et al., } \\
2016)\end{array}$ & Valladolid $^{4}$ & Units \\
\hline Capacity & 265,000 & 750,000 & $1,067,033$ & $\mathrm{PE}$ \\
$\mathrm{Q}$ & 72,000 & 162,465 & 213,408 & $\mathrm{~m} / \mathrm{d}$ \\
$\mathrm{S}_{\mathrm{I}}$ & 23.48 & 56.52 & 21.00 & $\mathrm{~g} \mathrm{COD} / \mathrm{m}^{3}$ \\
$\mathrm{~S}_{\mathrm{S}}$ & 107.85 & 153.25 & 205.00 & $\mathrm{~g} \mathrm{COD} / \mathrm{m}^{3}$ \\
$\mathrm{X}_{\mathrm{I}}$ & 93.22 & 89.98 & 15.00 & $\mathrm{~g} \mathrm{COD} / \mathrm{m}^{3}$ \\
$\mathrm{X}_{\mathrm{S}}$ & 251.65 & 357.59 & 122.00 & $\mathrm{~g} \mathrm{COD} / \mathrm{m}^{3}$ \\
$\mathrm{~S}_{\mathrm{NH}}$ & 32.85 & 45.60 & 19.40 & $\mathrm{~g} \mathrm{~N} / \mathrm{m}^{3}$ \\
$\mathrm{~S}_{\mathrm{ND}}$ & 0.00 & 0.00 & 4.94 & $\mathrm{~g} \mathrm{~N} / \mathrm{m}^{3}$ \\
$\mathrm{X}_{\mathrm{ND}}$ & 9.80 & 5.40 & 7.42 & $\mathrm{~g} \mathrm{~N} / \mathrm{m}^{3}$ \\
\hline
\end{tabular}

426 For the Valladolid influent wastewater, effluent measurements, such as total COD (TCOD eff), particulate $427 \mathrm{COD}\left(\mathrm{pCOD}_{\text {eff }}\right.$ ), total nitrogen (TN) and ammonium $\left(\mathrm{NH}_{4}^{+}\right)$, are collected (see SI.9 for details). While 428 fractionating the COD, it was assumed that the inert soluble COD remains constant (Bozkurt et al., 2016; 429 Roeleveld and van Loosdrecht, 2002). That means that $S_{\text {I }}$ in the influent is equal to sCODeff. Then, by 430 subtracting the $\mathrm{S}_{\mathrm{I}}$ from the influent soluble COD, the $\mathrm{S}_{\mathrm{S}}$ concentration is calculated. Furthermore, it is also 431 assumed that the influent $\mathrm{X}_{\mathrm{I}}$ is equal to $\mathrm{pCOD}_{\text {eff }}$ by neglecting the contribution of dead biomass $\left(\mathrm{X}_{\mathrm{P}}\right)$ to 432 particulate effluent COD. The biodegradable particulate COD $\left(\mathrm{X}_{\mathrm{S}}\right)$ is calculated by using the correlation $433 \mathrm{X}_{\mathrm{S}}=\mathrm{TCOD}-\left(\mathrm{S}_{\mathrm{S}}+\mathrm{S}_{\mathrm{I}}+\mathrm{X}_{\mathrm{I}}\right)$. For the organic nitrogen fractions, such as soluble organic nitrogen $\left(\mathrm{S}_{\mathrm{ND}}\right)$ and 434 particulate organic nitrogen $\left(\mathrm{X}_{\mathrm{ND}}\right)$, these are calculated by assuming $40 \%$ and $60 \%$ of the organic nitrogen 435 (which is the difference between $\mathrm{TN}$ and $\mathrm{NH}_{4}{ }^{+}$), respectively. Both COD and TN fractions for Valladolid 436 are summarized in Table 3. This influent fractionation procedure provides a basis to synthesize and design 437 optimal plant layout and further to robustify the solution by carrying out an uncertainty analysis, which is 438 the last step of the developed methodology. It is essential to highlight here that the Valladolid wastewater 439 influent is relatively diluted (i.e., low COD and TN concentration) compared to the Avedøre and Lynetten 440 WWTPs.

441 A database consisting of capital and operating costs of each technology and their design and operational 442 parameters is developed by referring to design handbooks, literature (Metcalf and Eddy, 2003; WEF, 2018) 443 and a commercial database (CapdetWorks 4.0). The inventories database consisting of cost information of 444 various technology presented in Table S2 (see SI) is reused here. The model library is customized by

\footnotetext{
${ }^{3}$ BIOFOS 2017 annual report (https://biofos.dk/wwwroot/media/1161/2017_biofos_aarsberetning.pdf)

${ }^{4}$ Personal communication
} 
including diverse alternative technologies classified in six different treatment tasks: carbon diversion, nutrient removal, sludge thickening, sludge stabilization, supernatant or reject water treatment, and sludge dewatering. The objective of the carbon diversion task is to ensure efficient carbon removal from mainstream to the $\mathrm{AD}$. This is quite crucial from an energy recovery point of view as higher carbon removal leads to higher biogas production in the AD (Behera et al., 2018; Wan et al., 2016). So for that reason, a combination of conventional technology (namely $P C$ and $H R A S$ ) and emerging technology (such as $R B F$ and $E R B F$ ) is considered. Likewise, for nutrient removal, both traditional activated sludge technology (i.e., $M L E$ ) and Anammox technology (such as IFAS and ELAN) are considered. The Anammox based technology is known for its low aeration energy requirement by following the partial nitritation mechanism (Chatterjee et al., 2016; Hoekstra et al., 2019; Malovanyy et al., 2015a; Morales et al., 2013).

Similarly for the sludge digestion, the $\mathrm{AD}$ is considered. A sludge thickener and a dewatering unit are also considered to handle the sludge thickening and dewatering tasks, respectively. The reject water which is generated from the dewatering unit contains 15 - 20\% of the entire plant nitrogen load (Fux et al., 2002) and is often recirculated to the mainstream. However, in recent years this stream is being treated more and more frequently by using Anammox technology (Lackner et al., 2014). So for these case studies a granule based Anammox technology (ELAN) is considered. The mechanisms and the mathematical models for the above-mentioned technologies are explained in Table 2.

462
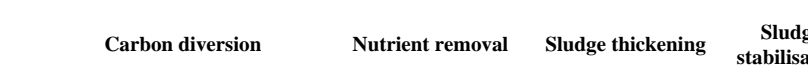
$\begin{array}{ccc}\text { Sludge } & \text { Supernatant water } \\ \text { stabilisation } & \text { Sludge dewatering } & \text { Resources }\end{array}$

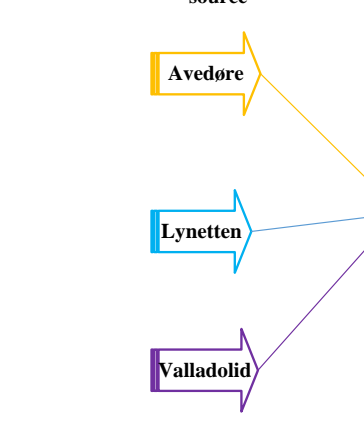

Figure 4 Superstructure representing the design space considering diverse technologies developed for the Aved $\phi$ re, Lynetten and Valladolid wastewater treatment plant case studies 


\subsection{Dimensioning of technology alternatives}

\section{9 \\ Dimensioning of primary treatment alternatives}

470 For the given influent load and characteristics, each unit is dimensioned. For the primary treatment 471 alternatives, such as PC, RBF, ERBF, and HRAS, the basic design dimensions mainly area and volume of 472 the tank are calculated using the design samples generated by the Monte Carlo procedure (as explained 473 above) and the design equations as discussed earlier. For the Avedøre influent, the volume of the PC (using 474 Equations 1-2) can vary from 4,406-11,526 $\mathrm{m}^{3}$. Likewise, for Lynetten, it can vary from 9,942 - 26,002 $475 \mathrm{~m}^{3}$ and for Valladolid in the range of $13,056-34,149 \mathrm{~m}^{3}$. Since the influent flow rate to the Valladolid 476 plant is significantly higher compared to the other plants (see Table 3), this is reflected in the volume 477 requirement. Emerging technologies like RBF and ERBF, which work based on sieving filtration 478 techniques, are efficient to divert more carbon from the mainstream to a sidestream. In the case of ERBF, 479 an additional tank (i.e., flocculation tank) is built before the RBF to enhance the solid separation by the 480 filter media. So for the Avedøre influent, the volume requirement for the RBF is $147 \mathrm{~m}^{3}$ (calculated using 481 Equations 3-4) and the ERBF is around $922 \mathrm{~m}^{3}$. Similarly, for the Lynetten and Valladolid influent, the 482 volume requirement of the RBF is $332 \mathrm{~m}^{3}$ and $436 \mathrm{~m}^{3}$, respectively. For ERBF, the volume requirements 483 are $2081 \mathrm{~m}^{3}$ (for Lynetten) and $2732 \mathrm{~m}^{3}$ (for Valladolid). Similarly, the HRAS works at short HRT and SRT 484 to facilitate biosorption, and its configuration consists of an aerobic tank and a settler to separate the 485 suspended solids. Using Equation 5, the total volume is calculated, which varies in the range of 2,413 $4864,852 \mathrm{~m}^{3}$ (for Avedøre), 5,445 - 10,959 $\mathrm{m}^{3}$ (for Lynetten) and 7,137 - 14,362 $\mathrm{m}^{3}$ (for Valladolid).

\section{Dimensioning of secondary treatment alternatives}

488 For the secondary treatment, technologies like MLE, IFAS, and ELAN are considered. The MLE is a 489 conventional activated sludge process which contains an anoxic tank (for denitrification), an aerobic tank 490 (for COD oxidation and nitrification) and a clarifier (for separating suspended biomass). Following 491 Equations 6-8, the total volume of the MLE is estimated to be 26,961-103,163 $\mathrm{m}^{3}$ (for Avedøre), 60,805$492232,678 \mathrm{~m}^{3}$ (for Lynetten) and 79,884 - 305,693 $\mathrm{m}^{3}$ (for Valladolid). Likewise, the IFAS and ELAN are 493 Anammox based technologies and operates partly with a partial nitritation and partly with denitrification 494 mechanism at low temperature. The IFAS reactor, which consists of an aerobic tank and a sedimentation 495 tank operates in continuous mode, and $\mathrm{K}_{1}$ type carriers are used to retain a high biomass concentration 496 inside the aerobic tank. Using Equations 1, 2 and 10 the total volume of IFAS is determined: 36,132 497 137,568 $\mathrm{m}^{3}$ (for Avedøre), 87,005 - 346,804 $\mathrm{m}^{3}$ (for Lynetten), 91,599 - 359,864 $\mathrm{m}^{3}$ (for Valladolid). 498 Unlike IFAS, the ELAN operates in sequential batch mode and uses granules to maintain a higher biomass 
499 concentration inside the reactor. Since the wastewater flow rate is high in the mainline, multiple ELAN

500 reactors can be arranged in parallel or stack manner based on the availability of civil engineering

501 advancement (Cabrera Jr et al., 2011). Applying Equation 9, the volume of mainstream ELAN is

502 approximated to 8,537-77,103 $\mathrm{m}^{3}$ (for Avedøre), 24,140 -208,187 $\mathrm{m}^{3}$ (for Lynetten) and 10,178-159,015

$503 \mathrm{~m}^{3}$ (for Valladolid).

504 Dimensioning of sludge stabilization alternatives

505 The sludge coming from primary and secondary treatment is further thickened and treated in AD units 506 which operate in CSTR mode. Applying Equation 11, the volume of the AD tank is calculated to 1,216 $50717,808 \mathrm{~m}^{3}$ (for Avedøre), 3,074 - 35,534 $\mathrm{m}^{3}$ (for Lynetten) and 2,404 - 40,473 $\mathrm{m}^{3}$ (for Valladolid).

\section{Dimensioning of sidestream treatment alternatives}

509 The reject water which comes out after dewatering is highly concentrated in $\mathrm{TN}$ and the $\mathrm{C} / \mathrm{N}$ ratio is low 510 and suitable for implementing Anammox technology. In this study, ELAN technology is considered for 511 enabling the anammox process. The major difference between mainstream and sidestream ELAN 512 technology dimensioning is the value of NLR range (see Table S3) which reflects in the calculated volume 513 range. Using Equation 9, the volume of sidestream ELAN is approximated to $420-18,058 \mathrm{~m}^{3}$ (for 514 Avedøre), 1,049-42,511 $\mathrm{m}^{3}$ (for Lynetten) and 1,289-51,701 $\mathrm{m}^{3}$ (for Valladolid).

517 As shown in Figure 3, all the three plants use a PC for the primary treatment task, the activated sludge 518 process for the secondary treatment task, a thickener, $\mathrm{AD}$ and a dewatering system are used to reduce the 519 sludge volume and produce biogas as primary energy recovery medium. The supernatant water is recycled 520 back to the primary clarifier. The purpose of designing the base case plant layout is to compare with the 521 potential plant layouts proposed by the integrated methodology (discussed in a later section). It is essential 522 to mention here that the detailed design data of the real plant was not accessible, and therefore each unit of 523 the base case plant layout is designed for each influent wastewater type (Avedøre, Lynetten, and Valladolid) 524 using the above-explained procedure. An example of Avedøre WWTP is presented in SI.5 (see SI). 


\section{RESULTS AND DISCUSSION}

526 Applying a combinatorial approach to the customized technology library, multiple plant layouts are 527 generated (see Figure 4). So, in total, there are 320 layouts and each layout to be simulated with 100 528 different design parameters sampled using the Monte Carlo procedure. Since the primary objective is to maximize energy recovery, using process knowledge, unrealistic layouts (for example layouts without AD 530 unit) are eliminated before simulation which help to reduce the number of simulations from 32,000 to 53124,000 for each influent wastewater type. Since the methodology uses computational demanding consensus 532 models, a systematic initialization strategy (see Figure 2) is applied to initialize each unit of the plant 533 layout. Daily average influent load values (as presented in Table 3) are used to perform plant-wide 534 simulations in the MATLAB-Simulink (2017a) environment. Since many process models equations are 535 highly nonlinear and mainly based on ODEs and PDEs, a stiff solver like ODE15s is preferred. To better 536 manage the computational budget, each model equation script is written in the $\mathrm{C}$ language, and the parallel 537 computing features of MATLAB are exploited. The simulation results are presented in a parallel plot (see 538 Figure 5 ) to visualize all the layouts (both feasible and unfeasible) and their corresponding design 539 performance. In the parallel plot the feasible plant layouts (green lines in Figure 5) are filtered by applying 540 effluent contraints (i.e., $\mathrm{COD}<100 \mathrm{~g} \mathrm{COD} / \mathrm{m}^{3}, \mathrm{TN}<10 \mathrm{~g} \mathrm{~N} / \mathrm{m}^{3}$ and $\mathrm{NH}_{4}{ }^{+}<1 \mathrm{~g} \mathrm{~N} / \mathrm{m}^{3}$ ) as explained earlier.

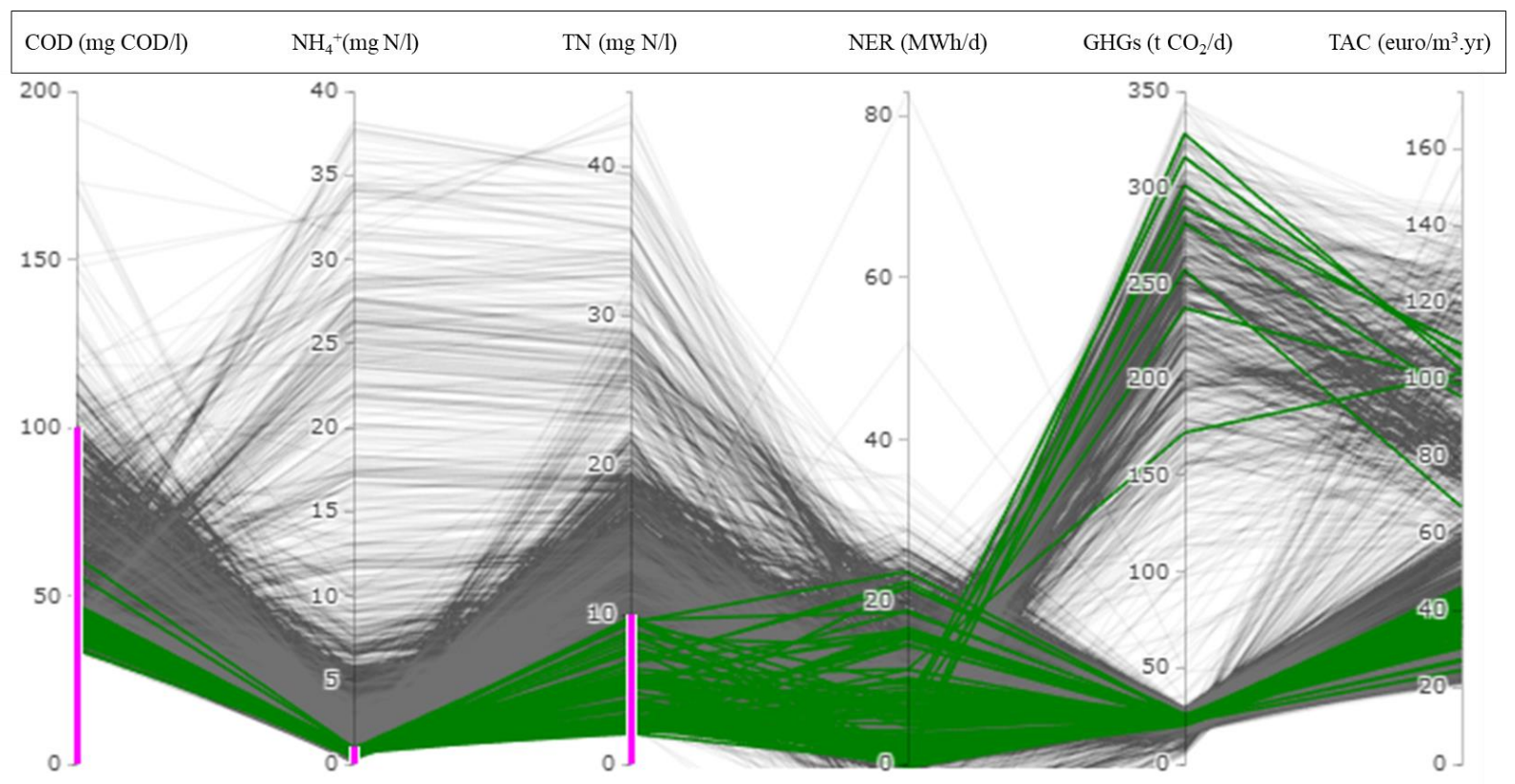

542 Figure 5 Displaying feasible plant layout (in green), unfeasible plant layout (in grey) and effluent constraints (in magenta) with 543 key performance indicators generated from Monte Carlo simulations for the Avedфre influent. 


\subsection{Deterministic plant layouts and their design selection}

\section{Objective 1: Building an energy recovery plant}

547 Since the primary objective is to maximize energy recovery, the optimization problem is formulated as a 548 single objective problem, as presented in Table S13 (see SI). The NER is calculated (see Equations S1-S3)

549 by subtracting the plant-wide energy consumption (accounting mainly for aeration, mixing and heating)

550 from the total energy production (in the form of heat and electricity) by combustion of the methane gas

551 from anaerobic digester in a CHP facility.

552 From Table 4, it is clear that the Lynetten wastewater influent has the highest theoretical energy potential

553 (considering $1 \mathrm{~kg}$ COD $2.73 \mathrm{kwh}$ for Avedøre and Valladolid WWTP, $1 \mathrm{~kg}$ COD $4.03 \mathrm{kwh}$ for Lynetten

554 WWTP, see SI.3 for details) to recover as the concentration of COD is relatively higher than the influent of

555 the other plants (see Table 3). The Lynetten plant recovers energy in the form of heat only, whereas the

556 other two plants recover energy in the form of electricity and heat. For each influent type, the top-ranked

557 plant layout proposed by the integrated methodology recovers more energy (see Table 4) than the existing

558 plant layout (i.e., base case). For example, in the case of Avedøre influent, the top plant layout (i.e., $H R A S$ -

559 IFAS-TH-AD-DW) recovers $16 \%$ more energy than the existing plant layout. Likewise, for Valladolid

560 wastewater influent, the existing plant layout consumes more energy than it produces. Whereas, the top

561 ranking plant layout (i.e., $H R A S-M L E-T H-A D-D W$ ) proposed by the integrated methodology recovers $24 \%$

562 more energy than the base case. This was possible because the PC unit (i.e., primary treatment) of the

563 existing plant layout is retrofitted with a HRAS unit, which provides an advantage to divert more carbon to

564 the AD compared to the base case layout. Since the Valladolid wastewater influent is diluted in terms of

565 COD concentration and the ratio of pCOD to SCOD is also low (see Table 3), the PC which works based

566 on gravity settling could not compete with HRAS which works based on biosorption (efficient at removing

567 both soluble and particulate COD). Moreover, the energy consumption of the HRAS is lower compared to

568 the PC as it operates at a very low DO set point thus avoiding excessive oxidation of COD (Jimenez et al., 569 2015).

570 For both the Avedøre and Lynetten WWTPs, a combination of HRAS as primary treatment technology and 571 IFAS as secondary treatment technology is a top choice to maximize the NER. Interestingly, for the 572 Valladolid wastewater influent, the methodology picks the HRAS and MLE combination. This could be 573 because the influent wastewater for the Valladolid plant has a lower TN concentration (see Table 3) 574 compared to the other two plants, and this does not limit the MLE performance on nitrogen removal (see

575 Table 4) although stringent effluent concentration constraints are imposed. Moreover, external carbon is 
576 also added to MLE for better denitrification. The net energy recovery of the Lynetten plant is highest among 577 the three plants since the COD mass present in the Lynetten influent is relatively higher (see Table 3 and 578 Table 4) and selecting HRAS as primary treatment alternative ensures efficient carbon diversion to the 579 AD unit. For the primary treatment task, ERBF is ranked as the second choice after HRAS as the addition 580 of polymer improves the suspended solids removal due to coagulation and flocculation mechanisms. It is 581 also evident from the results summary (i.e., Table 4) that sidestream treatment by ELAN technology helps 582 to achieve a higher energy recovery as it works based on the partial nitritation mechanism and needs 583 comparatively less aeration energy than complete nitrification (Lackner et al., 2014). Overall, these 584 outcomes demonstrate that the simulation-based optimization methodology can intelligently select 585 technologies based on geographical location and priorities. 


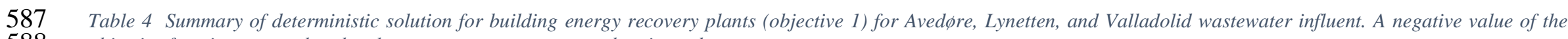
588 objective function means that the plant consumes more energy than it produces.

\begin{tabular}{|c|c|c|c|c|c|c|c|}
\hline \multirow{2}{*}{ Plant } & \multirow{2}{*}{ Process flow diagram } & \multirow{2}{*}{$\begin{array}{c}\text { Energy recovery } \\
\text { potential }(\mathrm{MWh} / \mathrm{d})\end{array}$} & \multicolumn{2}{|c|}{$\begin{array}{c}\text { Estimated energy recovery } \\
(\mathrm{MWh} / \mathrm{d})\end{array}$} & \multirow{2}{*}{$\begin{array}{l}\text { Net energy } \\
\text { recovery }(\%)\end{array}$} & \multirow{2}{*}{$\begin{array}{l}\text { OBJ function } \\
\text { (MWh/d) }\end{array}$} & \multirow{2}{*}{ Ranking } \\
\hline & & & $\begin{array}{c}\text { Heat } \\
(\mathrm{MWh} / \mathrm{d})\end{array}$ & $\begin{array}{l}\text { Electricity } \\
(\mathrm{MWh} / \mathrm{d})\end{array}$ & & & \\
\hline \multirow{6}{*}{ Avedøre } & $P C-M L E-T H-A D-D W$ (Base case) & 93.56 & 20.57 & 16.16 & $9 \%$ & 8.29 & - \\
\hline & HRAS-IFAS-TH-AD-DW (L1) & 93.56 & 23.56 & 18.51 & $25 \%$ & 23.74 & 1 \\
\hline & HRAS-IFAS-TH-AD-DW-ELANS (L2) & 93.56 & 21.86 & 17.18 & $23 \%$ & 21.92 & 2 \\
\hline & ERBF-MLE-TH-AD-DW (L3) & 93.56 & 20.33 & 15.97 & $12 \%$ & 11.65 & 3 \\
\hline & ERBF-ELANM-TH-AD-DW-ELANS (L4) & 93.56 & 16.88 & 13.26 & $11 \%$ & 10.26 & 4 \\
\hline & ERBF-IFAS-TH-AD-DW-ELANS (L5) & 93.56 & 17.42 & 13.69 & $10 \%$ & 8.95 & 5 \\
\hline \multirow{6}{*}{ Lynetten } & $P C-M L E-T H-A D-D W$ (Base case) & 430.16 & 180.97 & 0.00 & $24 \%$ & 101.69 & - \\
\hline & HRAS-IFAS-TH-AD-DW (L1) & 430.16 & 203.71 & 0.00 & $35 \%$ & 152.09 & 1 \\
\hline & HRAS-IFAS-TH-AD-DW-ELANS (L2) & 430.16 & 189.26 & 0.00 & $32 \%$ & 139.23 & 2 \\
\hline & ERBF-MLE-TH-AD-DW-ELANS (L3) & 430.16 & 176.87 & 0.00 & $27 \%$ & 118.13 & 3 \\
\hline & ERBF-MLE-TH-AD-DW (L4) & 430.16 & 171.34 & 0.00 & $25 \%$ & 108.45 & 4 \\
\hline & ERBF-IFAS-TH-AD-DW (L5) & 430.16 & 155.18 & 0.00 & $22 \%$ & 93.88 & 5 \\
\hline \multirow{6}{*}{ Valladolid } & $P C-M L E-T H-A D-D W$ (Base case) & 211.49 & 38.07 & 29.91 & $-9 \%$ & -19.62 & - \\
\hline & HRAS-MLE-TH-AD-DW (L1) & 211.49 & 48.22 & 37.89 & $14 \%$ & 28.63 & 1 \\
\hline & HRAS-IFAS-TH-AD-DW (L2) & 211.49 & 40.26 & 31.64 & $11 \%$ & 22.92 & 2 \\
\hline & HRAS-IFAS-TH-AD-DW-ELANS (L3) & 211.49 & 34.85 & 27.38 & $7 \%$ & 13.93 & 3 \\
\hline & ERBF-IFAS-TH-AD-DW (L4) & 211.49 & 39.55 & 31.07 & $1 \%$ & 2.18 & 4 \\
\hline & ERBF-MLE-TH-AD-DW-ELANS (L5) & 211.49 & 39.48 & 31.02 & $1 \%$ & 1.18 & 5 \\
\hline
\end{tabular}



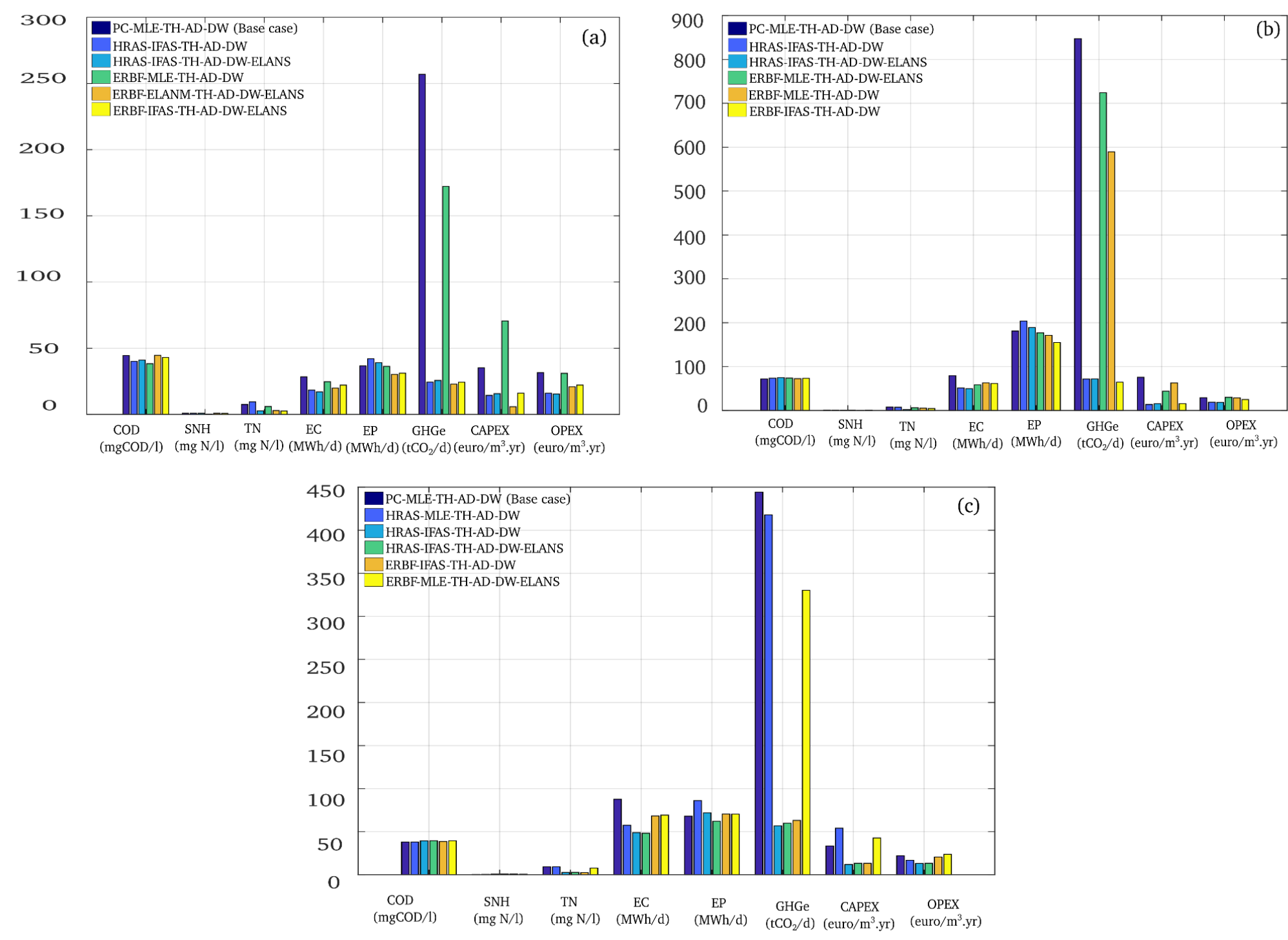

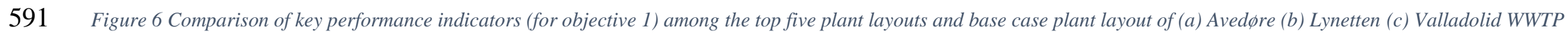


593 For the second objective, there are three significant priorities, which are cost, sustainability, and energy 594 recovery. Here the cost accounts for both capital cost (mainly equipment and construction) and operational 595 (such as electricity, chemicals, etc.) cost. The problem is treated as multi-objective optimization (see Table 596 S13) where the NER needs to be maximized, and the other two objectives need to be minimized. A weightbased multi-criteria strategy is applied to find optimal solutions for each influent wastewater. Before that, each objective is normalized (using a min-max approach) between 0 to 1 , and equal weights are assigned ( $\left.w_{1}=w_{2}=w_{3}=0.33\right)$. These weights are flexible to change based on user priorities.

Figure S4 and Table S14 (see SI) summarise the comparison of potential plant layouts performance against the base case design of three different influents. Key findings are as follows:

- To build an economically sustainable energy recovery plant, the layout $H R A S-I F A S-T H-A D-$ $D W$ is the top choice identified by the methodology irrespective of the influent. This highlights that the combination of efficient carbon recovery with mainstream Anammox technology can be a promising one to build economical sustainable energy recovery WWTPs. Apart from that, other units such as ERBF (uses a polymer to enhance carbon diversion) and ELAN are also promising alternatives.

- Plant layout including the MLE unit is not favorable for building an economical sustainable energy recovery factory as it emits a high quantity of GHGs compared to the other secondary treatment units (see Figure S4) and the capital cost is significantly higher as well (see Table S2). Studies (Campos et al., 2016; Okabe et al., 2011) also confirm that the mainstream Anammox process emits less $\mathrm{N}_{2} \mathrm{O}$ gas.

- For the Valladolid influent, other plant layouts (except top 1) have a negative NER value, which means the plant consumes more energy than it can produce. Moreover, the net energy recovery by the top ranking plant layout is approximately $11 \%$, which is low compared to the other two plants. This is because the Valladolid influent wastewater has a comparatively low COD concentration, which is a critical bottleneck for harvesting surplus energy. The current practice in the Valladolid WWTP is to import external sludge/food waste to the AD unit to enhance biogas production. 


\subsection{Stochastic analysis of selected plant layouts and respective designs}

622 The plant layouts chosen in the previous step (i.e., step 5) are selected based on a yearly average influent 623 load which is subjected to change due to population growth, climate change, etc. Moreover, in practice the 624 influent load to the WWTP changes daily/weekly/monthly. Therefore it is critical to ensure that the plant

625 layout proposed by the integrated methodology should be robust to handle unforeseen events. In this 626 context, uncertainty in the influent wastewater is used as a basis to perform stochastic analysis on selected 627 plant layouts resulting from the deterministic analysis (i.e., step 5) and has also been used in other studies 628 (Al et al., 2019b; Bozkurt et al., 2016; Castillo et al., 2016a; Sin et al., 2009).

\section{Uncertainty characterization}

630 In the three WWTP influent, mainly COD and ammonium are considered to vary, and their upper and lower 631 bounds are defined in Table S15. Since the actual distribution of the considered influent fractions is not 632 known, a uniform probability distribution is assigned to each component. Furthermore, a 30\% variation 633 around the deterministic value was assumed for these components. The Latin Hypercube Sampling (LHS) 634 technique with no correlation among the components is used to sample the distribution, and the sample size 635 is limited to 100 . The biodegradable particulates $\left(X_{S}\right)$ fraction is estimated by subtracting the sum of $S_{S}, X_{I}$, 636 and $S_{\text {I }}$ from the total influent COD to ensure that the COD mass balance is respected.

637 The selected top five plant layouts in the deterministic analysis (i.e., step 5) are further simulated using the 638 Monte Carlo technique to quantify the uncertainty on the objective functions under influent uncertainties. 639 The results of all the three plants are presented in terms of mean and 95\% confidence interval for each 640 objective function to redefine the ranking based on the stochastic analysis.

\section{Ranking of promising plant layouts including uncertainty for objective 1}

642 The objective is to build an energy recovery plant for each influent wastewater. Therefore the performance 643 of a layout is ranked based on the mean value of the NER (generated from stochastic analysis). While 644 ranking, it is assumed that a layout having more than $20 \%$ effluent constraint violations should be given 645 less priority. Table 5 and Figure 7 summarize the stochastic analysis results, which are discussed as 646 follows: 
- For Avedøre and Lynetten influent, some potential plant layouts (for example HRAS - IFAS - TH $A D-D W$ ) selected in the deterministic step are not able to handle the influent uncertainty, whereas it works well for the Valladolid influent. This could be because of the relatively diluted influent wastewater for the Valladolid WWTP (see Table 3) which does not put any extra stress on the plant.

- Stochastic analyses reveal (based on Avedøre and Lynetten results) that the plant layout promising a high energy recovery may not always respect the effluent discharge regulations.

- For the Avedøre and Lynetten WWTP, stochastic analysis suggests that sidestream treatment with Anammox technology (i.e., ELAN) should be considered to handle the uncertainty in the nitrogen load better.

- The energy recovery after stochastic analyses steps is further reduced compared to the deterministic analyses, which is mainly due to the variation in influent COD load. This demonstrates the importance of evaluating influent uncertainties on the potential energy recovery.

- Stochastic ranking differs from the deterministic ranking, especially for Avedøre and Lynetten, which highlight its importance in the overall methodology and helps to contemplate the real situation. 
664 Table 5 Comparison of the deterministic and stochastic ranking of potential plant layouts for building an energy recovery plant (objective 1). A negative value of the objective 665 function means plant consumes more energy than it produces.

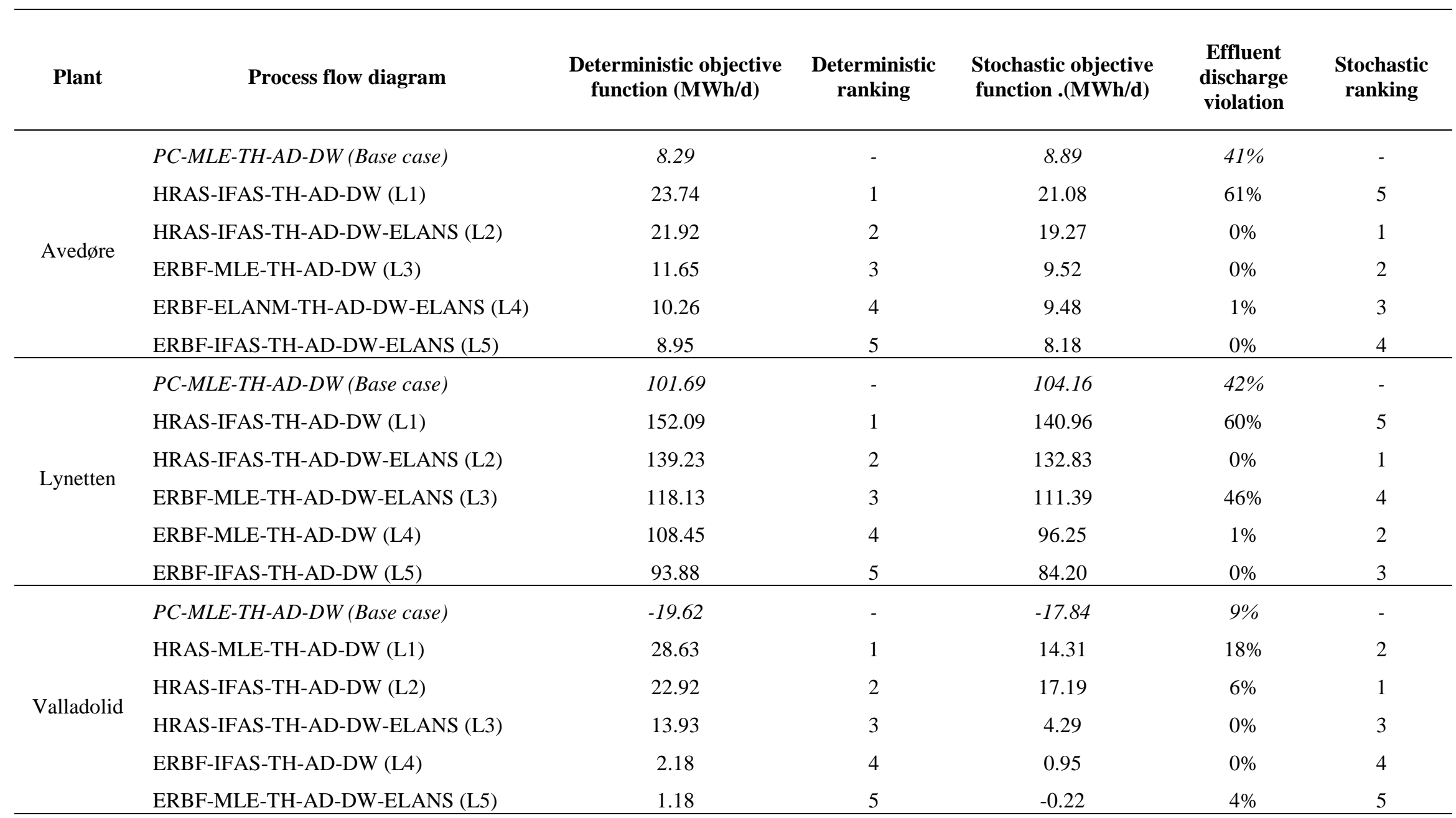



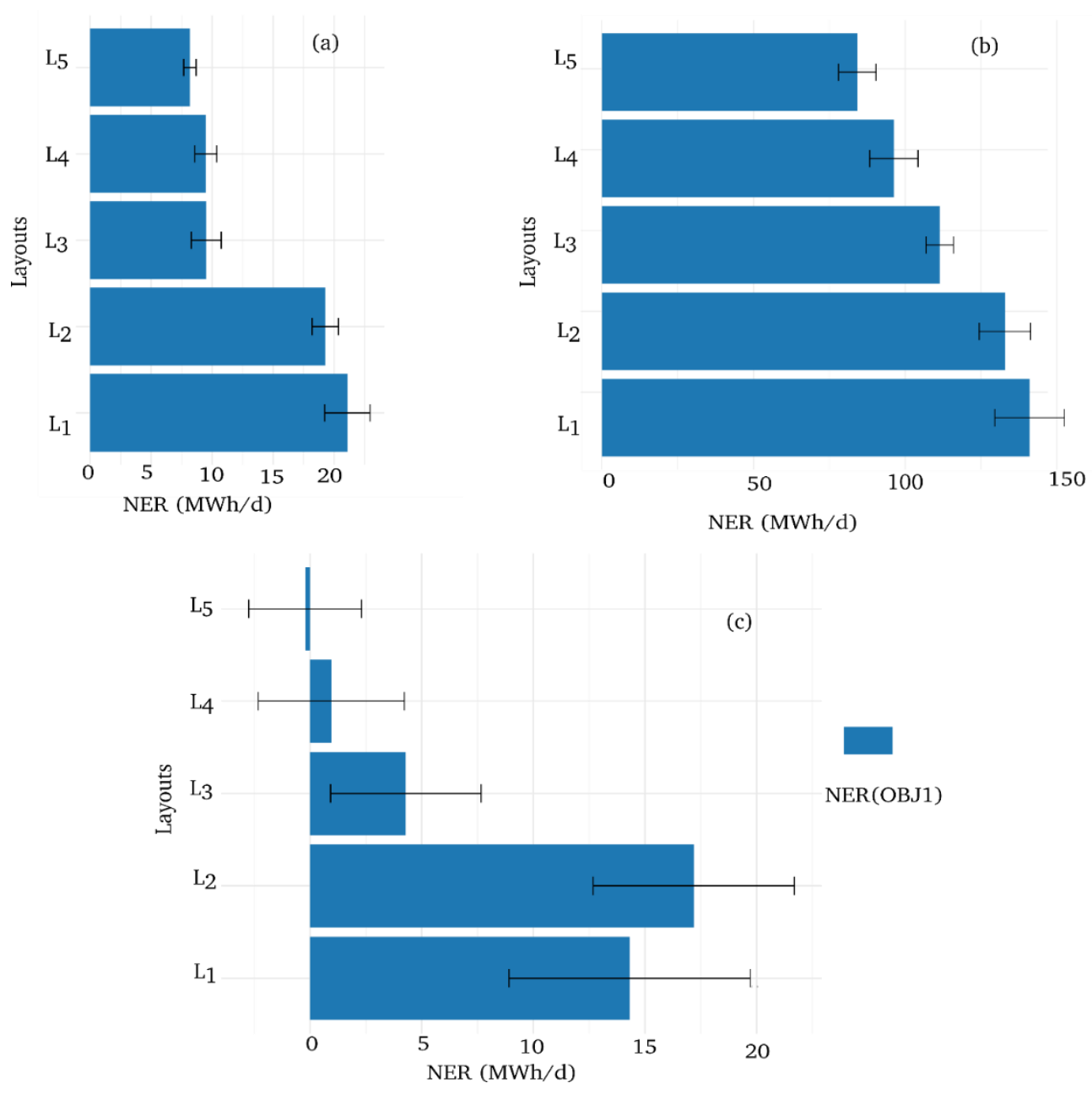

668 Figure 7 Mean value of net energy recovery (NER) of the top five ranking plant layouts and their respective 95\% confidence interval

669 (thin black bars) obtained from the influent wastewater uncertainty analysis: (a) Aved $\phi r e(b)$ Lynetten (c) Valladolid WWTP

Ranking of promising plant layouts including uncertainty for objective 2

671 Objective 2 aims to build an economical sustainable energy recovery plant, which has three priorities, namely cost (TAC), GHGs emission, and NER. Similar to deterministic analysis, the mean values of TAC,

673 NER, and GHGs for each layout are normalized, and a weighted sum is calculated (applying Equation 17).

674 The effluent discharge violation is relaxed up to $20 \%$ while ranking the plant layout. The key findings from 675 Figure S5 and Figure S16 are the following:

676 - For Avedøre and Lynetten, a common plant layout (HRAS - IFAS - TH - AD - DW- ELANS) is selected by the methodology which is similar to the findings for objective 1 (see Table 5). On the other hand, for the Valladolid influent, the $H R A S-I F A S-T H-A D-D W$ plant layout is selected as most promising plant layout which may be due to the low influent ammonium load (see Table S15) compared to the other influents. Therefore no sidestream treatment is required for the 

enhanced carbon recovery technology with mainstream and sidestream Anammox technology is a suitable combination to build an energy recovery WWTP.

- Furthermore, most of the potential plant layout candidates (for the Valladolid influent) have a negative NER (see Figure S5), which means that building an economically sustainable energy recovery plant may not be a smart choice, especially when the influent wastewater is diluted in terms of COD load. To achieve a surplus energy production, the plant will need to supplement the influent COD load with external carbon sources (sludge waste, food waste, etc.).

\section{CONCLUSIONS}

690 The proposed process synthesis (SPDLab) tool has been successfully applied to study and analyze design retrofit scenarios for three full-scale WWTPs- two from Denmark and one from Spain. The steps involved in the methodology are systematically demonstrated by formulating their realistic scenarios from designing an energy recovery plant perspective. The sole objective behind the scenario formulation is to illustrate the

694 influence of several factors such as end-user priorities, uncertainty in the influent wastewater load, 695 government regulation, etc. on the decision-making process. A model library incorporating diverse technologies (in total 11 technologies) combing conventional as well as emerging technologies, is applied to select and design an energy recovery plant for Avedøre, Lynetten, and Valladolid wastewater influent.

698 In total 320 alternative plant layouts representing different combinations of treatment units are generated 699 and rigorously simulated with 100 different design parameter sets to find the optimal plant layout for each 700 influent type.

701 The key advantages of the proposed integrated methodology are: it handles a wide range of computational 702 demanding consensus models, handles a broad range of design and operating conditions, provides higher 703 visibility on performance at each stage (such as primary, secondary treatment, etc.) of treatment technology, 704 calculates effluent quality indicators in a more reliable way. Major conclusions from these case studies are 705 given below:

- Higher carbon recovery favors higher energy production. HRAS and ERBF presence in top five layouts is dominating as primary treatment alternative technology.

- For all the three influent types, higher carbon recovery technology like HRAS and ERBF are more suitable for building an energy recovery plant because higher carbon diversion leads to higher biogas production from $\mathrm{AD}$. 
- Along with efficient carbon recovery technology, mainstream and sidestream Anammox technology (such as ELAN and IFAS) contribute to overall energy production by significantly reducing the aeration energy demand compared to a conventional activated sludge process.

- Compared to current designs, the methodology identified optimal retrofitting solutions with promising improvements in net energy recovery (NER) as much as three folds for Avedøre and 1.5 fold increase for Lynetten WWTP. While the stochastic analysis indicated that the potential improvements are decreased, given the influent load variation, there is still a strong case for considering and pilot testing emerging concepts of carbon recovery in WWTP plants for enhancing biogas production in $\mathrm{AD}$.

- The COD present in influent wastewater can be a suitable indicator for deciding whether to build an energy recovery plant or not. Compared to Danish WWTPs (Avedøre and Lynetten), the Spanish WWTP (Valladolid) has low net energy recovery because influent wastewater is diluted.

- The plant layouts proposed by the SPDLab tool ensures higher energy recovery potential, lower GHGs emission, and cost than the existing real plant layouts. Simulation-based optimization is consequently useful for taking decision intelligently by recognizing the existing variability

- Uncertainty in the influent wastewater composition greatly influences the ranking of plant layouts, which emphasizes the importance to include it in the methodology. However, it is essential to note that the uncertainty bound is highly subjective and other design inputs such as safety factor, effluent requirements, etc. as suggested by Flores-Alsina et al. (2012) should be judiciously defined.

730 Indeed, treatment objectives, such as micro-pollutants removal (e.g. refractory toxic organics like 731 pharmaceuticals, pesticides, personal care products, etc.), require the adaptation of tertiary treatment

732 techniques (membrane processes, advanced oxidation techniques, etc.) which in turn, can be adapted for 733 different treatment objectives along the process layout (e.g. membrane assisted biological process-MBR, 734 pre-ozonation of organics, etc.). Therefore, future work can focus on expansion of the technology library. 735 Moreover, the deterministic (step 5) and stochastic (step 6) ranking of the proposed integrated methodology 736 can be integrated with a multi-objective optimization solver to find optimal plant layout and designs.

\section{SOFTWARE AVAILABILITY}

738 Availability: Development version available on GitHub

\section{9




\section{ACKNOWLEDGMENTS}

741 The authors acknowledge funding from the Water Joint Programming Initiative under the PIONEER_STP

742 project as well as funding from the EU Horizon 2020 research and innovation program under the Marie

743 Skłodowska-Curie grant agreement no.675251.

\section{REFERENCES}

745

746

747

748

749

750

751

752

753

754

755

756

757

758

759

760

761

762

763

764

765

766

767

Agrawal, S., Seuntjens, D., Cocker, P. De, Lackner, S., Vlaeminck, S.E., 2018. Success of mainstream partial nitritation/anammox demands integration of engineering, microbiome and modeling insights. Curr. Opin. Biotechnol. 50, 214-221. https://doi.org/10.1016/J.COPBIO.2018.01.013

Al, R., Behera, C.R., Gernaey, K.V., Sin, G., 2019a. Towards development of a decision support tool for conceptual design of wastewater treatment plants using stochastic simulation optimization. Comput. Aided Chem. Eng. 46, 325-330. https://doi.org/10.1016/B978-0-12-818634-3.50055-2

Al, R., Behera, C.R., Zubov, A., Gernaey, K.V., Sin, G., 2019b. Meta-modeling based efficient global sensitivity analysis for wastewater treatment plants - An application to the BSM2 model. Comput. Chem. Eng. 127, 233-246. https://doi.org/10.1016/J.COMPCHEMENG.2019.05.015

Alasino, N., Mussati, M.C., Scenna, N., 2007. Wastewater Treatment Plant Synthesis and Design. Ind. Eng. Chem. Res. 46, 7497-7512. https://doi.org/10.1021/ie0704905

Balkema, A.J., Preisig, H.A., Otterpohl, R., Lambert, F.J., 2002. Indicators for the sustainability assessment of wastewater treatment systems. Urban Water 4, 153-161. https://doi.org/10.1016/S14620758(02)00014-6

Batstone, D.J., Keller, J., Angelidaki, I., Kalyuzhnyi, S.V., Pavlostathis, S.G., Rozzi, A., Sanders, W.T., Siegrist, H., Vavilin, V.A., 2002. The IWA Anaerobic Digestion Model No 1 (ADM1). Water Sci. Technol. 45, 65-73. https://doi.org/https://doi.org/10.2166/wst.2002.0292

Behera, C.R., Santoro, D., Gernaey, K.V., Sin, G., 2018. Organic carbon recovery modeling for a rotating belt filter and its impact assessment on a plant-wide scale. Chem. Eng. J. 334, 1965-1976. https://doi.org/10.1016/j.cej.2017.11.091

Belia, E., Amerlinck, Y., Benedetti, L., Johnson, B., Sin, G., Vanrolleghem, P.A., Gernaey, K.V., Gillot, S., Neumann, M.B., Rieger, L., 2009. Wastewater treatment modelling: Dealing with uncertainties. Water Sci. Technol. 60, 1929-1941. https://doi.org/https://doi.org/10.2166/wst.2009.225 
Benedetti, L., Bixio, D., Claeys, F., Vanrolleghem, P.A., 2008. Tools to support a model-based

Castillo, A., Porro, J., Garrido-Baserba, M., Rosso, D., Renzi, D., Fatone, F., Gómez, V., Comas, J., Poch,

Boiocchi, R., Behera, C.R., Sherratt, A., DeGroot, C.T., Gernaey, K.V., Sin, G. and Santoro, D., 2020. Dynamic model validation and advanced polymer control for rotating belt filtration as primary treatment of domestic wastewaters. Chemical Engineering Science, p.115510. https://doi.org/10.1016/j.ces.2020.115510

Bozkurt, H., Quaglia, A., Gernaey, K.V., Sin, G., 2015. A mathematical programming framework for early stage design of wastewater treatment plants. Environ. Model. Softw. 64, 164-176. https://doi.org/10.1016/J.ENVSOFT.2014.11.023

Bozkurt, H., van Loosdrecht, M.C.M., Gernaey, K.V., Sin, G., 2016. Optimal WWTP process selection for treatment of domestic wastewater-A realistic full-scale retrofitting study. Chem. Eng. J. 286, 447458. https://doi.org/https://doi.org/10.1016/j.cej.2015.10.088

Cabrera Jr, E., Dane, P., Haskins, S., Theuretzbacher-Fritz, H., 2011. Benchmarking Water Services. IWA publishing, London, UK.

Campos, J.L., Valenzuela-Heredia, D., Pedrouso, A., Val del Rio, A., Belmonte, M., Mosquera-Corral, A., 2016. Greenhouse gases emissions from wastewater treatment plants: minimization, treatment, and prevention. J. Chem. 2016.

Cao, Y., van Loosdrecht, M.C.M., Daigger, G.T., 2017. Mainstream partial nitritation-anammox in municipal wastewater treatment: Status, bottlenecks, and further studies. Appl. Microbiol. Biotechnol. 101, 1365-1383. https://doi.org/10.1007/s00253-016-8058-7

Castillo, A., Cheali, P., Gómez, V., Comas, J., Poch, M., Sin, G., 2016a. An integrated knowledge-based and optimization tool for the sustainable selection of wastewater treatment process concepts. Environ. Model. Softw. 84, 177-192. https://doi.org/10.1016/j.envsoft.2016.06.019

M., 2016b. Validation of a decision support tool for wastewater treatment selection. J. Environ. Manage. 184, 409-418. https://doi.org/https://doi.org/10.1016/j.jenvman.2016.09.087

Chamberlain, B.C., Carenini, G., Oberg, G., Poole, D., Taheri, H., 2014. A decision support system for the design and evaluation of sustainable wastewater solutions. IEEE Trans. Comput. 63, 129-141. https://doi.org/10.1109/TC.2013.140

Chatterjee, P., Ghangrekar, M.M., Rao, S., 2016. Development of anammox process for removal of nitrogen 
from wastewater in a novel self-sustainable biofilm reactor. Bioresour. Technol. 218, 723-730. https://doi.org/10.1016/j.biortech.2016.07.002

802 Comas, J., Alemany, J., Poch, M., Torrens, A., Salgot, M., Bou, J., 2004. Development of a knowledgebased decision support system for identifying adequate wastewater treatment for small communities. Water Sci. Technol. 48, 393-400. https://doi.org/https://doi.org/10.2166/wst.2004.0887

Dominguez, D., Gujer, W., 2006. Evolution of a wastewater treatment plant challenges traditional design concepts. Water Res. 40, 1389-1396. https://doi.org/10.1016/J.WATRES.2006.01.034

Eberl, H., Morgenroth, E., Noguera, D., Picioreanu, C., Rittmann, B., van Loosdrecht, M., Wanner, O., 2006. Mathematical modeling of biofilms. IWA publishing London, London, UK.

Ferrer, J., Seco, A., Serralta, J., Ribes, J., Manga, J., Asensi, E., Morenilla, J.J., Llavador, F., 2008. DESASS: A software tool for designing, simulating and optimising WWTPs. Environ. Model. Softw.

\section{3, 19-26. https://doi.org/https://doi.org/10.1016/j.envsoft.2007.04.005}

Flores-Alsina, X., Corominas, L., Neumann, M.B., Vanrolleghem, P.A., 2012. Assessing the use of activated sludge process design guidelines in wastewater treatment plant projects: A methodology based on global sensitivity analysis. Environ. Model. Softw. 38, 50-58. https://doi.org/10.1016/J.ENVSOFT.2012.04.005

Flores-Alsina, X., Rodríguez-Roda, I., Sin, G., Gernaey, K.V., 2008. Multi-criteria evaluation of wastewater treatment plant control strategies under uncertainty. Water Res. 42, 4485-4497. https://doi.org/10.1016/J.WATRES.2008.05.029

Frutiger, J., Andreasen, J., Liu, W., Spliethoff, H., Haglind, F., Abildskov, J., Sin, G., 2016. Working fluid selection for organic Rankine cycles-Impact of uncertainty of fluid properties. Energy 109, 987-997. https://doi.org/https://doi.org/10.1016/j.energy.2016.05.010

Frutiger, J., Cignitti, S., Abildskov, J., Woodley, J.M., Sin, G., 2019. Computer-aided molecular productprocess design under property uncertainties - A Monte Carlo based optimization strategy. Comput.

Fux, C., Boehler, M., Huber, P., Brunner, I., Siegrist, H., 2002. Biological treatment of ammonium-rich

828 Garrido-Baserba, M., Reif, R., Molinos-Senante, M., Larrea, L., Castillo, A., Verdaguer, M., Poch, M., 829 2016. Application of a multi-criteria decision model to select of design choices for WWTPs. Clean 830 Technol. Environ. Policy 18, 1097-1109. https://doi.org/https://doi.org/10.1007/s10098-016-1099-x 
831 Gernaey, K. V., Jeppsson, U., Vanrolleghem, P.A., Copp, J.B., 2014. Benchmarking of Control Strategies 832 for Wastewater Treatment Plants, Scientific and Technical Report No. 23. IWA Publishing, London, 833 UK. https://doi.org/10.2166/9781780401171

834 Guest, J.S., Skerlos, S.J., Barnard, J.L., Beck, M.B., Daigger, G.T., Hilger, H., Jackson, S.J., Karvazy, K., 835 Kelly, L., Macpherson, L., Mihelcic, J.R., Pramanik, A., Raskin, L., Van Loosdrecht, M.C.M., Yeh, 836 D., Love, N.G., 2009. A new planning and design paradigm to achieve sustainable resource recovery

838 Guo, L., Vanrolleghem, P.A., 2014. Calibration and validation of an activated sludge model for greenhouse

Hamouda, M.A., Anderson, W.B., Huck, P.M., 2009. Decision support systems in water and wastewater

Hoekstra, M., Geilvoet, S.P., Hendrickx, T.L.G., van Erp Taalman Kip, C.S., Kleerebezem, R., van Loosdrecht, M.C.M., 2019. Towards mainstream anammox: Lessons learned from pilot-scale research at WWTP Dokhaven. Environ. Technol. 40, 1721-1733.

Iman, L.R., Conover, W.J., 1982. A distribution-free approach to including rank correlation among input variables. Commun. Stat. Comput.

11 , $311-334$. https://doi.org/https://doi.org/10.1080/03610918208812265

Jimenez, J., Miller, M., Bott, C., Murthy, S., De Clippeleir, H., Wett, B., 2015. High-rate activated sludge system for carbon management-Evaluation of crucial process mechanisms and design parameters. Water Res. 87, 476-482. https://doi.org/https://doi.org/10.1016/j.watres.2015.07.032

Lackner, S., Gilbert, E.M., Vlaeminck, S.E., Joss, A., Horn, H., van Loosdrecht, M.C.M., 2014. Full-scale partial nitritation/anammox experiences - An application survey. Water Res. 55, 292-303. https://doi.org/10.1016/j.watres.2014.02.032 Joss, A., 2016. Mainstream partial nitritation and anammox: Long-term process stability and effluent quality at low temperatures. Water Res. 101, 628-639. https://doi.org/10.1016/j.watres.2016.05.005 
862 Lotti, T., Kleerebezem, R., Hu, Z., Kartal, B., de Kreuk, M.K., van Erp Taalman Kip, C., Kruit, J., 863 Hendrickx, T.L.G., van Loosdrecht, M.C.M., 2014. Pilot-scale evaluation of anammox-based 864 mainstream nitrogen removal from municipal wastewater. Environ. Technol. 36, 1167-77. 865 https://doi.org/10.1080/09593330.2014.982722

866 Malovanyy, A., Trela, J., Plaza, E., 2015a. Mainstream wastewater treatment in integrated fixed film 867 activated sludge (IFAS) reactor by partial nitritation/anammox process. Bioresour. Technol. 198, 478-

Metcalf, E., Eddy, H., 2003. Wastewater engineering: Treatment and reuse, Tata McGraw-Hill Publishing

Morales, N., Rogalla, F., Campos, J.L., 2013. Elan technology: a step forward in the quest for energy self-

Malovanyy, A., Yang, J., Trela, J., Plaza, E., 2015b. Combination of upflow anaerobic sludge blanket 487. https://doi.org/10.1016/j.biortech.2015.08.123 suffiency in WWTP. https://doi.org/10.2166/wst.2013.795.

Okabe, S., Oshiki, M., Takahashi, Y., Satoh, H., 2011. N2O emission from a partial nitrification-anammox process and identification of a key biological process of $\mathrm{N} 2 \mathrm{O}$ emission from anammox granules. Water Res. 45, 6461-6470.

Otterpohl, R., Raak, M., Rolfs, T., 1994. A mathematical model for the efficiency of the primary clarification, in: Proceedings of IAWQ 17th Biennial International Conference.

Poch, M., Comas, J., Rodríguez-Roda, I., Sànchez-Marrè, M., Cortés, U., 2004. Designing and building real

Pons, M.N., Spanjers, H., Jeppsson, U., 1999. Towards a benchmark for evaluating control strategies in wastewater treatment plants by simulation. Comput. Chem. Eng. 23, S403-S406. https://doi.org/10.1016/S0098-1354(99)80099-4

Puchongkawarin, C., Gomez-Mont, C., Stuckey, D.C., Chachuat, B., 2015. Optimization-based methodology for the development of wastewater facilities for energy and nutrient recovery. Chemosphere 140, 150-158. https://doi.org/https://doi.org/10.1016/j.chemosphere.2014.08.061 processing networks. Ph.D Thesis, Technical University of Denmark, Department of Chemical and 
Biochemical, Copenhagen, Denmark.

894 Rawal, N., Duggal, S.K., 2016. Life cycle costing assessment-based approach for selection of wastewater 895 treatment units. Natl. Acad. Sci. Lett. 39, 103-107. https://doi.org/https://doi.org/10.1007/s40009016-0429-1

897 Rivas, A., Irizar, I., Ayesa, E., 2008. Model-based optimisation of wastewater treatment plants design. Environ. Model. Softw. 23, 435-450. https://doi.org/10.1016/j.envsoft.2007.06.009

Roeleveld, P.J., van Loosdrecht, M.C.M., 2002. Experience with guidelines for wastewater characterisation in The Netherlands. Water Sci. Technol. 45, 77-87.

Shim, J.P., Warkentin, M., Courtney, J.F., Power, D.J., Sharda, R., Carlsson, C., 2002. Past, present, and 902 future of decision support technology. Decis. Support Syst. 33, 111-126. https://doi.org/10.1016/S0167-9236(01)00139-7

Sin, G., Gernaey, K.V., Neumann, M.B., van Loosdrecht, M.C.M., Gujer, W., 2011. Global sensitivity analysis in wastewater treatment plant model applications: Prioritizing sources of uncertainty. Water Res. 45, 639-651. https://doi.org/10.1016/j.watres.2010.08.025

Sin, G., Gernaey, K.V., Neumann, M.B., van Loosdrecht, M.C.M., Gujer, W., 2009. Uncertainty analysis

910 Smitshuijzen, J., Pérez, J., Duin, O., van Loosdrecht, M.C.M., 2016. A simple model to describe the performance of highly-loaded aerobic COD removal reactors. Biochem. Eng. J.

913 Takács, I., Patry, G.G., Nolasco, D., 1991. A dynamic model of the clarification-thickening process. Water Res. 25, 1263-1271. https://doi.org/10.1016/0043-1354(91)90066-Y

915 Tang, S.L., Wong, C.L., Ellis, K.V., 1997. An optimization model for the selection of wastewater and sludge treatment alternatives. Water Environ. J. 11, 14-20. https://doi.org/https://doi.org/10.1111/j.17476593.1997.tb00083.x

Vangsgaard, A.K., Mutlu, A.G., Gernaey, K.V., Smets, B.F., Sin, G., 2013. Calibration and validation of a model describing complete autotrophic nitrogen removal in a granular SBR system. J. Chem. Technol. Biotechnol. 88, 2007-2015. https://doi.org/https://doi.org/10.1002/jctb.4060 
924 Vázquez-Padín, J.R., Morales, N., Gutiérrez, R., Fernández, R., Rogalla, F., Barrio, J.P., Campos, J.L., 925 Mosquera-Corral, A., Méndez, R., 2014. Implications of full-scale implementation of an anammox926 based process as post-treatment of a municipal anaerobic sludge digester operated with co-digestion. 927 Water Sci. Technol. 69, 1151-1158. https://doi.org/10.2166/wst.2013.795

928 Vidal, N., Bañares-Alcántara, R., Rodríguez-Roda, I., Poch, M., 2002. Design of wastewater treatment 929 plants using a conceptual design methodology. Ind. Eng. Chem. Res. 41, 4993-5005. 930 https://doi.org/10.1021/ie010652b

931 Wan, J., Gu, J., Zhao, Q., Liu, Y., 2016. COD capture: A feasible option towards energy self-sufficient 932 domestic wastewater treatment. Sci. Rep. 6, 1-9. https://doi.org/10.1038/srep25054

933 WEF, A., 2018. Design of Water Resource Recovery Facilities, Sixth Edition. McGraw-Hill Education.

934 Zeng, G., Jiang, R., Huang, G., Xu, M., Li, J., 2007. Optimization of wastewater treatment alternative 935 selection by hierarchy grey relational analysis. J. Environ. Manage. 82, 250-259. 936 https://doi.org/10.1016/J.JENVMAN.2005.12.024

937 Zhou, Y., Oehmen, A., Lim, M., Vadivelu, V., Ng, W.J., 2011. The role of nitrite and free nitrous acid 938 (FNA) in wastewater treatment plants. Water Res. 45, 4672-4682. 939 https://doi.org/10.1016/j.watres.2011.06.025

940 